\title{
Effect of surface radiation on the breakdown of steady natural convection flows in a square, air-filled cavity containing a centred inner body
}

\author{
Hua Sun, Eric Chénier and Guy Lauriat* \\ Laboratoire de Modélisation et Simulation Multi Echelle \\ (MSME UMR-CNRS 8208) \\ Université Paris-Est \\ 5 Bvd Descartes, Champs sur Marne, F-77454 Marne-la-Vallée Cedex 2 \\ ( ${ }^{*}$ Corresponding author: lauriat@univ-mlv.fr, phone: 331609572 69, Fax: 331609572 94)
}

\begin{abstract}
The physical model considered in the present numerical work is a square air-filled cavity cooled from below and above, with a heated square body located at the cavity center. The aim is to establish the effects of radiation interchanges amongst surfaces on the transition from steady, symmetric flows about the cavity centerline to complex periodic flows. Owing to the low temperature differences involved $(1 \mathrm{~K} \leq \Delta \mathrm{T} \leq 5 \mathrm{~K})$, the two-dimensional model is based on the Boussinesq approximation and constant thermophysical fluid properties at room temperature. The cavity walls are assumed grey and diffuse. The flow structure is investigated for various Rayleigh numbers, emissivities of the wall surfaces and sizes of the inner body. The results clearly establish the influence of surface radiation, both for steady and unsteady flows. For the geometry and thermal boundary conditions considered, the Rayleigh number for the transition to unsteady flows is considerably increased under the influence of radiation. This work underlines the difficulties in comparing experimental data and numerical solutions for gas-filled cavities partly subjected to wall heat flux boundary conditions.
\end{abstract}

Keywords: Natural convection, Surface radiation, Numerical study, Unsteady flows, Bifurcations

Abbreviated title: Coupled radiation and free convection 


\section{Nomenclature}

A aspect ratio of the inner body, $A=W / L$

B dimensionless radiosity

k fluid thermal conductivity (W/m K)

L length of the cavity side-walls (m)

$\mathrm{N}_{r} \quad$ radiation number

$\mathrm{Nu} \quad$ Nusselt number

$\mathrm{P} \quad$ dimensionless motion pressure

Pr Prandtl number, $\operatorname{Pr}=v / \alpha$

$\mathrm{q}_{\mathrm{r}, \mathrm{i}} \quad$ net dimensionless radiative heat flux along surface "i"

$\mathrm{Ra}_{\mathrm{L}} \quad$ cavity Rayleigh number, $\mathrm{Ra}_{\mathrm{L}}=\mathrm{g} \beta \Delta \mathrm{TL}^{3} / \alpha \nu$

$\mathrm{Ra}_{\mathrm{t}} \quad$ top Rayleigh number, $\mathrm{Ra}_{\mathrm{t}}=\mathrm{A}^{3} \mathrm{Ra}_{\mathrm{L}}$

t dimensionless time

$\mathrm{T} \quad$ temperature $(\mathrm{K})$

$\mathrm{T}_{0} \quad$ reference temperature, $\mathrm{T}_{0}=\left(\mathrm{T}_{\mathrm{h}}+\mathrm{T}_{\mathrm{c}}\right) / 2(\mathrm{~K})$

V dimensionless velocity vector

W length of the sides of the inner body (m)

$(\mathrm{x}, \mathrm{y}, \mathrm{z})$ Cartesian coordinates with the origin at cavity center.

Greeks

$\alpha \quad$ thermal diffusivity $\left(\mathrm{m}^{2} / \mathrm{s}\right)$

$\varepsilon \quad$ emissivity

$\Delta \mathrm{T} \quad$ temperature difference, $\Delta \mathrm{T}=\mathrm{T}_{\mathrm{h}}-\mathrm{T}_{\mathrm{c}}(\mathrm{K})$

$\eta \quad$ temperature ratio, $\eta=\mathrm{T} / \mathrm{T}_{0}$

$\psi \quad$ dimensionless streamfunction

$\rho \quad$ density $\left(\mathrm{kg} / \mathrm{m}^{3}\right)$

$\sigma \quad$ Stefan-Boltzmann constant $\left(\mathrm{W} / \mathrm{m}^{2} \mathrm{~K}^{4}\right)$

$\theta \quad$ dimensionless temperature difference

Subscripts

c cold wall

cV convection

h hot wall

$\mathrm{r} \quad$ radiation

s $\quad$ side wall

Superscripts

* dimensional quantity 


\section{Introduction}

In this paper, the results of a numerical study of combined natural convection and surface radiation from an inner body enclosed in a cavity are reported. Relevant to the present work are engineering applications such as electronic cooling, manufacturing processes, building energy components ... in which natural convection heat transfer between a gas-filled enclosure and inner bodies occurs. Considerable research has been performed for fully partitioned cavities or obstructions in the form of partial baffles centered vertically in a vertical enclosure and, for various shaped obstructions located within a rectangular cavity because the obstructions may increase as well as decrease the heat transfer. For tall cavities with multiple partitions, the numerical study by Rabhi et al. [1] demonstrates the effects of surface radiation on the overall thermal resistance of partitioned cavities.

Relevant to the geometry investigated in the present study are the work by House et al. [2] who considered the influence of a centered square obstruction in a differentially heated cavity, and those by Deng and Tang [3], Ha et al. [4] and Lee et al. [5,6]. More recently Bouafia and Daube [7] reconsidered this class of problem by using the low Mach number approximation [8] for large temperature differences between a heated body within a rectangular cavity with cold vertical walls and insulated horizontal walls. This approximation allows to take density variations into account in all terms of the conservation equations, and it based on a pressure decomposition into a leading term, assumed spatially uniform, and a second-order, fluctuating term.

Studies on combined natural convection and surface radiation from heated body inside a cavity are more scarse (for an overview of recent references, see Bouali et al. [9], Lauriat and Desrayaud [10], Mezrhab et al. [11]) while the interaction of natural convection and radiation in participating media was the purpose of many studies (see Colomer et al. [12], for example). The paper by Mezrhab et al. [13] may be considered as the most related study to the present work. They considered a differentially-heated cavity of square cross-section containing a conducting, centered square body. Amongst the conclusions drawn for this particular configuration, the effect of the inner body on the flow field and heat transfer was shown much important when surface radiation exchanges were taken into account. In the range of Rayleigh number considered, it is also shown that radiation augments the fluid velocities in comparison with those obtained for an empty cavity. It what follows, it will be shown that surface radiation has opposite effects for the boundary conditions considered herein, and on the stability properties of the flow. 
There is still lacking information about the influence of radiation exchanges between surfaces, even when considering the simplest model based on gray, diffuse surfaces. For example, although many experimental, numerical and theoretical works are available in the archival literature, some questions remain open, in particular the relevance in comparisons between experimental data and numerical simulations when the experiments are conducted for gas-filled cavities (generally air at an average temperature close to room temperature). Up-to-date flow visualization techniques are widely used (Cesini et al. [14], Leplat et al. [15]), but the requirements are generally that two parallel walls should be transparent to laser beams in order to allow optical access to the cavity. Except for small scale experimental set-up for which glasses having high infra-red (I.R.) transmittance can be used (such as KRS-5 or KBr crystal material), the experiments are often conducted by using common glass window or polycarbonate sheets, opaque at I.R. wavelengths corresponding to room temperature. As it is well known, these materials have also a high emissivity (close to one) for this wavelength domain. Therefore, owing to the low temperature differences involved in many experimental work (typically of the order of $10 \mathrm{~K}$ around ambient temperature in air-filled cavities), it was assumed that radiation exchanges amongst the walls have a negligible influence on the flow and temperature fields. Such an assumption may be justified if a great care is taken during both designs of the experimental set-up and measurements. Unfortunately, experiments are still conducted to determine routes to chaos (bifurcation phenomena) or to validate direct numerical simulations (DNS) of weakly turbulent flows without taking into account the right boundary conditions at the semi-transparent walls and, consequently, the effects of surface radiation on the critical parameters.

The purpose of this investigation is to emphasize the effect of radiation exchanges amongst surfaces on the stability properties of natural convection flows around an inner body. To this end, a numerical analysis is performed for natural convection from a single horizontal, heated solid body of square section immersed at the center of an air-filled cavity of square cross section, as shown schematically in Fig.1. The solid body is assumed at uniform hot temperature, $\mathrm{T}_{\mathrm{h}}$, close to ambient temperature $(300 \mathrm{~K})$. The vertical side walls are adiabatic while the lower and upper horizontal walls are isothermally cooled at a temperature $T_{c}$, not very different from $T_{h}$. We are particularly interested in the flow transitions (or bifurcations) which occur when the Rayleigh number is increased through increases in the temperature difference between the inner body and the cold horizontal surfaces $\left(\Delta \mathrm{T}=\mathrm{T}_{\mathrm{h}}-\mathrm{T}_{\mathrm{c}}\right)$ within the range $[1 \mathrm{~K}, 5 \mathrm{~K}]$ for a square cavity whose side length is $\mathrm{L}=10 \mathrm{~cm}$, containing a body having a side length $\mathrm{W}$ ranging from $\mathrm{W}=2 \mathrm{~cm}$ to $\mathrm{W}$ $=8 \mathrm{~cm}$, as in the experiments conducted recently by Ménard [16] and Leplat [17]. Since the 
study concerns an air-filled cavity, the Rayleigh number based on L and on physical properties of air at $298.15 \mathrm{~K}$ is very close to $\mathrm{Ra}_{\mathrm{L}}=10^{5} \Delta \mathrm{T}$.

The influence of radiation exchanges amongst the surfaces on the flow field originates in the thermal boundary conditions applied at the vertical side walls. By assuming the side-walls as isothermal, radiation has no effect on the flow structure. On the other hand, noticeable interaction between convection and radiation arises if heat flux boundary conditions are applied at some parts of the cavity walls, while the emissivities of the surfaces are not close to zero. In order to reduce the heat losses at the non isothermal parts of the walls, most of the experimental set-ups were designed such that the non-isothermal walls may be assumed as adiabatic, so that the number of parameters involved is reduced. Unfortunately, the adiabatic conditions are the worst for experimental studies of natural convection in gas-filled cavities when the emissivities of the thermally insulated surfaces are high.

The present study being restricted to two-dimensional flows, the Rayleigh number should not be too high in order that this assumption may be assumed valid, as in Boufia and Daube [7]. For $\mathrm{Ra}_{\mathrm{L}}$ much higher than the supercritical value corresponding to the geometric configuration investigated, the experimental and numerical results by Leplat $[17,18]$ for $\mathrm{A}=\mathrm{W} / \mathrm{L}=0.4$ and $\Delta \mathrm{T} \approx 9.6 \mathrm{~K}$ show indeed that complex 3D flows develop. We believe that the effect of surface radiation would be similar to those discussed in the present study because larger temperature differences imply also larger effects of radiation on the topology of chaotic flows. A comprehensive study of such flows is beyond the scope of the present work.

\section{Governing equations}

The dimensions of the box and of the heated inner solid body and, the temperature difference are such that the flows generated are assumed two-dimensional, incompressible, laminar and that the Boussinesq approximation can be applied with constant fluid properties. The surfaces are supposed to be gray and diffuse and, separated by a radiatively nonparticipating medium. The net radiative heat flux distributions are calculated by using the well-known radiosity-irradiation method $[19,20]$. The governing equations can be written in dimensionless form as

$$
\begin{aligned}
& \nabla \cdot \mathrm{V}=0 \\
& \frac{\partial \mathrm{V}}{\partial t}+\mathrm{V} \cdot \nabla \mathrm{V}=-\nabla P+\operatorname{Pr} \nabla^{2} \mathrm{~V}-R a_{L} \operatorname{Pr} \theta \frac{\boldsymbol{g}}{|\boldsymbol{g}|}
\end{aligned}
$$




$$
\frac{\partial \theta}{\partial t}+\mathrm{V} \cdot \nabla \theta=\nabla^{2} \theta
$$

The above equations were cast in dimensionless form by scaling length, time, velocity, pressure and temperature difference $\left(\mathrm{T}-\mathrm{T}_{0}\right)$ by $\mathrm{L}, \mathrm{L}^{2} / \alpha, \mathrm{V}_{0}=\alpha / \mathrm{L}, \rho \mathrm{V}_{0}^{2}$ and $\Delta \mathrm{T}$. Therefore, the dimensionless variables in the above equations are defined as

$$
t=\frac{\alpha t^{*}}{L^{2}}, \quad x=\frac{x^{*}}{L}, \quad y=\frac{y^{*}}{L}, \quad P=\frac{P^{*} L^{2}}{\rho \alpha^{2}}, \quad \theta=\frac{T-T_{0}}{T_{h}-T_{c}}
$$

where superscript «*» stands for dimensional quantities.

For the boundary conditions, no-slip velocity conditions are applied at the boundaries. When radiative interchanges among surfaces are accounted for, the thermal boundary conditions at the adiabatic walls must include the contribution of the net radiative heat flux. The net radiative heat flux distributions are axially symmetric provided that the flow is also axially symmetric. Otherwise, the radiosity distributions being dependent on the wall temperature profiles, dissymmetry in the flow field implies different radiative heat flux distributions at the vertical walls. In what follows, the scale for the radiative flux and radiosity is $\sigma \mathrm{T}_{0}^{4}$. The net radiative flux density along the surfaces of the diffuse-gray and opaque, vertical walls is written in the following dimensionless form:

$$
q_{r, i}=B_{i}-\sum_{j=1}^{N} \int_{S_{j}} B_{j}\left(\mathbf{r}_{\mathbf{j}}\right) K\left(\mathbf{r}_{\mathbf{i}}, \mathbf{r}_{\mathbf{j}}\right) d S_{j}
$$

where $B_{i}\left(\mathbf{r}_{\mathrm{i}}\right)$ is the dimensionless radiosity along surface $S_{i}$ :

$$
B_{i}\left(\mathbf{r}_{\mathbf{i}}\right)=\varepsilon_{i} \eta_{i}^{4}\left(\mathbf{r}_{\mathbf{i}}\right)+\left(1-\varepsilon_{i}\right) \sum_{j=1}^{N} \int_{S_{j}} B_{j}\left(\mathbf{r}_{\mathbf{j}}\right) K\left(\mathbf{r}_{\mathbf{i}}, \mathbf{r}_{\mathbf{j}}\right) d S_{j}
$$

where $\eta_{i}=\mathrm{T} / \mathrm{T}_{0}$ is the dimensionless temperature used for non-dimensionalizing the radiation part of the problem. The position vectors $\mathbf{r}_{\mathrm{i}}$ and $\mathbf{r}_{\mathrm{j}}$ denote the locations of elementary surfaces $d S_{i}$ and $d S_{j}$ on surfaces $S_{i}$ and $S_{j}$. The kernel function $K$ is defined as

$$
K\left(\mathbf{r}_{\mathbf{i}}, \mathbf{r}_{\mathbf{j}}\right)=\frac{d F_{d S_{i}-d S_{j}}}{d S_{j}}
$$

where $d F_{d S i-d S j}$ is the elementary view factor between $d S_{\mathrm{i}}$ and $\mathrm{d} \mathrm{S}_{\mathrm{j}}$ [20]. The $\mathrm{N}$ surfaces involved are the four walls of the cavity and the four sides of the inner body (i.e. $\mathrm{N}=8$ ).

The thermal boundary conditions are: 
$\theta=0.5$ at the inner body surface

$\theta=-0.5$ at the bottom and top horizontal surfaces at $y=-0.5$ and 0.5

$\left.\frac{\partial \theta}{\partial x}\right|_{y_{i}}=N_{r} q_{r, i}\left(y_{i}\right)$ at the adiabatic cavity side walls at $x=-0.5$ and 0.5

where $N_{r}=\sigma T_{0}^{4} L / k \Delta T$ is the radiation number. Whatever the $N_{r}$-value, the radiation effects may be discarded provided that the wall emissivity is very small.

The local Nusselt number along the walls is defined as:

$$
\begin{aligned}
N u_{i}\left(\boldsymbol{r}_{i}\right) & =-\boldsymbol{n}_{i} \cdot \nabla \theta+N_{r} q_{r, i}\left(\boldsymbol{r}_{i}\right) \\
& =N u_{c v}\left(\boldsymbol{r}_{i}\right)+N u_{r}\left(\boldsymbol{r}_{i}\right)
\end{aligned}
$$

where $\mathbf{n}_{\mathrm{i}}$ is the outward unit normal to wall " $i$ ". $\mathrm{Nu}_{\mathrm{cv}}$ and $\mathrm{Nu}_{\mathrm{r}}$ are the local convective and radiative Nusselt number, respectively. The average Nusselt number along a side wall is obtained by integration along the wall.

\section{Numerical methods}

Calculations were carried-out using the control volume code ANSYS FLUENT (Ansys Fluent 12 User'Guide [21]). Results of the simulations were collected and processed by employing inhouse softwares.

Collocated, rectangular, structured and weakly non-uniform grids were used on account of the expected flow structures. The Quadratic Upwind Interpolation for Convective Kinematics scheme (QUICK) was used for the advective and transport terms in order to compute third-order truncation error of the convected variables [22]. The velocity-pressure coupling was solved with the Pressure-Implicit with Splitting of Operators algorithm (PISO [23]) since transient computations were carried out, and the pressure was calculated with a body-force weighted scheme which is well adapted for natural convection flows.

The governing equations were solved either in their transient form, sequentially, with a secondorder decoupled implicit scheme (segregated solver) or using the implicit coupled scheme for purely steady approaches. In both cases, the implicit treatment of the equations was achieved using an iterative solver with a convergence criterion of $10^{-6}$ and $10^{-10}$ for unsteady and steady problems, respectively. The radiation fluxes were updated once every 10 iterations of the iterative solver ensuring the implicit coupling of all the variables and the radiosity field was 
assumed converged when its maximum normalized changes from one sweep to the next was less than $10^{-6}$.

Validations of the results for pure natural convection flows were carried out by comparison of our results with those reported in Leplat [16]. A mesh study for uniform grids was also conducted using a steady approach and the dependences of the wall heat fluxes on the grid resolution are reported in Table 1. Comparison of these results with those obtained with a $150 \times 150$ weakly non-uniform grid (see Tab. 2 for $\varepsilon_{\mathrm{c}}=\varepsilon_{\mathrm{s}}=0$ ) shows a good agreement and justifies the use of this latter mesh which presents a good compromise between accuracy and computational loads.

The computational costs depend strongly on the flow regime. For steady flows, at $\operatorname{Ra}_{\mathrm{L}} \leq 2.10^{5}$ for pure natural convection with a $150 \times 150$ grid, for example, the CPU-time is about $2900 \mathrm{~s}$ to reach convergence on a workstation with a mono-processor $(2.8 \mathrm{GHz})$ and $4 \mathrm{~GB}$ of RAM. With radiation taken into account, the CPU-time is increased up to about $3500 \mathrm{~s}$. For unsteady flows, one thousand time-steps requires about 7 hours for pure natural convection and more than 8 hours with radiation

\section{Results}

All the computations were carried out for a square cavity of $\mathrm{L}=10 \mathrm{~cm}$ side-length, containing a centered, square body made in aluminum, having a side length ranging from $\mathrm{W}=2 \mathrm{~cm}$ to $\mathrm{W}=$ $8 \mathrm{~cm}$. The average temperature of air was kept fixed at $\mathrm{T}_{0}=298.15 \mathrm{~K}\left(\alpha=2.1510^{-5} \mathrm{~m}^{2} / \mathrm{s}, \operatorname{Pr}=\right.$ 0.71). The temperature difference between the hot inner body and the cold horizontal surfaces $\left(\Delta \mathrm{T}=\mathrm{T}_{\mathrm{h}}-\mathrm{T}_{\mathrm{c}}\right.$ ) was varying between $2 \mathrm{~K}$ and $4 \mathrm{~K}$. The emissivity of the inner body surface was $\varepsilon_{\mathrm{h}}=0.05$ for all of the cases investigated. The reference heat flux used for the dimensionless heat flux is thus $\mathrm{q}_{\mathrm{ref}}=0.2607 \Delta \mathrm{T}\left(\mathrm{W} / \mathrm{m}^{2}\right)$ and the radiation number is $\mathrm{N}_{\mathrm{r}}=1718 / \Delta \mathrm{T}$.

\subsection{Case $A=0.4$ : steady flows}

In that case, the flow is stable up to a Rayleigh number very close to $\operatorname{Ra}_{c}=2.10^{5}$ (i.e. $\Delta \mathrm{T} \approx 2$ $\mathrm{K})$ when neglecting radiant interchanges among the surfaces. Below this Rayleigh number, the flow is steady and symmetric about the vertical centerline of the cavity (reflection symmetry, Boufia and Daube [7]).

\subsubsection{Pure natural convection}

The isothermal patterns and streamlines displayed in Fig. $2 \mathrm{a}$ for $\mathrm{Ra}_{\mathrm{L}}=2.10^{5}$ and $\mathrm{A}=0.4$ show that the flow structure consists in two symmetric, counter-rotating, Rayleigh-Bénard type cells at the upper part of the cavity delimited by two large cells rotating in opposite directions along the 
vertical walls (clockwise at the right-hand side). These side-cells extend up and penetrate into the thermally stratified fluid layer below the inner body. For this case, the Rayleigh numbers based on the distance between the cavity and inner solid walls $(\mathrm{e}=3 \mathrm{~cm})$ are $\mathrm{Ra}_{\mathrm{t}}=5400$ for the bottom and upper parts of the cavity. Therefore, $\mathrm{Ra}_{\mathrm{t}}$ being larger than 1708 , potentially unstable flows occur within the horizontal upper part of the cavity (note that $\mathrm{Ra}_{\mathrm{t}}=1708$ for $\Delta \mathrm{T}=0.63 \mathrm{~K}$ ). From our computations and those reported in Leplat [17], the flow undergoes a bifurcation leading to a periodic motion as it will be discussed in the next section. About the fluid layers along the vertical sides, the effective Rayleigh numbers, $\mathrm{Ra}_{\mathrm{s}}$, could be evaluated from a characteristic temperature difference $\Delta T_{\mathrm{s}}=\mathrm{T}_{\mathrm{h}}-\mathrm{T}_{\text {side, }}$, where $\mathrm{T}_{\text {side }}$ is the average temperature of the parts A"B" or C'D" (see Fig. 1) of the adiabatic walls facing the inner body $\left(\operatorname{Ra}_{\mathrm{s}}=2700 \Delta \mathrm{T}_{\mathrm{s}}\right)$. These parts being obviously the hottest parts of the side walls, $\mathrm{Ra}_{\mathrm{s}}$ is smaller than $\mathrm{Ra}_{\mathrm{t}}$ as can be seen in Fig. 3 from which it is found that $\mathrm{Ra}_{\mathrm{s}} \approx 2295\left(\Delta \mathrm{T}_{\mathrm{s}} \approx 0.85 \mathrm{~K}\right)$ when neglecting surface-to-surface radiation exchanges $\left(\varepsilon_{\mathrm{c}}=\varepsilon_{\mathrm{s}}=\varepsilon_{\mathrm{h}}=0\right)$.

\subsubsection{Effects of surface radiation}

The effects of radiation were considered for four cases: first, the asymptotic case of four black surfaces of the cavity $\left(\varepsilon_{\mathrm{c}}=\varepsilon_{\mathrm{s}}=1\right)$. This case corresponds to the emissivities of the wall surfaces in the experimental set-up used in Ménard [16] and Leplat [17], i.e. black cold horizontal walls, side walls made of double-glazing windows. Second, the isothermal, cold horizontal surfaces made in copper could have been polished instead of being painted in black. In that case, we assumed that their emissivities could be close to $\varepsilon_{\mathrm{c}}=0.05$ while double-glazing windows are still used to allow flow visualization $\left(\varepsilon_{\mathrm{s}}=1\right)$. Third, we considered that the four side walls have the same emissivity $\varepsilon_{\mathrm{c}}=\varepsilon_{\mathrm{s}}=0.05$ (insulated vertical walls covered with aluminum sheets, for example). Fourth, we assumed that the four cavity walls were slightly oxidized $\left(\varepsilon_{\mathrm{c}}=\varepsilon_{\mathrm{s}}=0.1\right)$. The averaged convective Nusselt numbers at the various surfaces shown in Fig.1 are reported in Table 2 for these four cases. Due to space limitation, the streamlines and isothermal patterns are plotted in Fig. $2 \mathrm{~b}$ and $2 \mathrm{c}$ for the cases $\left(\varepsilon_{\mathrm{c}}=0.05, \varepsilon_{\mathrm{s}}=1\right)$ and $\left(\varepsilon_{\mathrm{c}}=\varepsilon_{\mathrm{s}}=1\right)$ only.

Comparisons between Figs. 2a (pure natural convection) and $2 \mathrm{~b}$ shows a rather small effect of radiation exchanges on the flow field, and effects of radiation restricted to small fluid layers along the vertical adiabatic walls where the impingements of the isotherms are not perpendicular to the black surfaces. The largest effects of radiation are seen at the bottom part of the cavity where the thermal stratification differs. However, these effects of radiation may be assumed to have a small influence on the main flow circulations, and thus on the bifurcation path to unsteady 
flows. The reason is that the temperature distribution along the vertical walls does not differ much from that for pure natural convection, as can be seen in Fig. 3.

When the cold horizontal walls are recovered with a black paint $\left(\varepsilon_{\mathrm{c}}=1\right)$, a comparison between Fig. 2a (no radiation) and $2 \mathrm{c}$ shows that the fluid recirculations in the vertical side layers are noticeably increased (about 30\%). The explanation can be found in the decrease in the adiabatic wall temperatures, as can be seen in Fig. 3. It is found that $\mathrm{Ra}_{\mathrm{s}}$ increases then up to 4185 due to the reduction of about $1.3 \mathrm{~K}$ in the mean temperature of segment A"B". Since the emissivity of the hot inner body is very small $\left(\varepsilon_{\mathrm{h}}=0.05\right)$, the heating of the adiabatic walls by radiation is insignificant. On the other hand, the view factors between the horizontal cold surfaces and the vertical wall surfaces being quite large $\left(\mathrm{F}_{\mathrm{c}, \mathrm{a}} \approx 0.46\right.$ as a rough approximation $)$ due to the relatively small size of the inner body, the radiation exchanges between the vertical sides and the cold horizontal surfaces lead to significant decreases in the temperatures of the adiabatic walls. Radiation has a rather weak effect on the Rayleigh-Bénard cells because the two horizontal, top surfaces $\mathrm{BC}$ and $\mathrm{B}^{\prime} \mathrm{C}$ ' are isothermal.

Finally, since the effect of the radiation exchanges amongst the cold and adiabatic surfaces are to decrease the adiabatic surfaces temperature, it could be assumed that the case of a cavity with four cold walls at $T_{c}=297.15 \mathrm{~K}$ is an asymptotic configuration. In that case, surface radiation has no effect. Through comparisons between Fig. 2a, 2c and 2d, it can be deduced that the flow structure predicted for isothermal, cold vertical walls (Fig. 2d) is closer to the experimental conditions than that for pure natural convection in a cavity with two adiabatic, non-radiating vertical surfaces (Fig. 2a). The values of the convective Nusselt number at the surfaces of the inner body, reported in Table 2, support this observation. The stabilizing influence of radiation can be indeed exemplified by the increase in the fluid recirculations produced within the vertical layers which, in turn, leads to higher convective heat flux at surfaces A'B' and C'D'.

The increases in fluid recirculations along the side walls caused by radiation can be depicted by the variation of the maximum value of the streamfunction (Fig. 4). It was found that the flow rate increases almost linearly with the emissivity according to the smoothed law:

$$
\psi_{\max }=1.464+0.339 \varepsilon \quad \text { for } \mathrm{A}=0.4, \varepsilon=\varepsilon_{\mathrm{c}}=\varepsilon_{\mathrm{s}} \text { and } \mathrm{Ra}_{\mathrm{L}}=3.10^{5}
$$

The question is whether two-dimensionality of the flow field may be invoked. In order to check this assumption, 3D simulations were carried out for a $18 \mathrm{~cm}$-depth cavity, i.e. the length of the experimental set-up in [17]. Isothermal patterns are displayed in Fig. 5a for pure natural 
convection and in Fig. $5 \mathrm{~b}$ in the case of four black walls. These patterns for the middle plane section $\left(\mathrm{z}^{*}=0\right)$ and two symmetrical sections $\left(\mathrm{z}^{*}=-4.5 \mathrm{~cm}\right.$ and $\left.\mathrm{z}^{*}=4.5 \mathrm{~cm}\right)$ clearly show that $3 \mathrm{D}$ effects can be neglected over most of the cavity depth for $\mathrm{Ra}=2.10^{5}$. The influence of surface radiation does not differ from that found through 2D-simulations.

The conclusion which could be drawn is that the experiments conducted for four black walls, two adiabatic vertical walls and two cold isothermal walls, lead to measurements far from those expected for pure natural convection.

\subsection{Case A = 0.4: unsteady flows}

\subsubsection{Pure natural convection}

As described in the previous sections, the flow structure consists in two symmetric counterrotating Rayleigh-Bénard cells above the heated body, delimited by two large circulation flows along the vertical walls. In the classical Rayleigh-Bénard problem between infinite plates, the natural dimensionless wavelength based on the fluid thickness is $2 \pi / 3.117 \approx 2$ at the conduction/convection transition, and then increases with Ra. In the present configuration, the Rayleigh-Bénard cell stretching is limited from below by the size of the inner body ( $\mathrm{W}=4 \mathrm{~cm}$ ) and also by the distance between the heated body and the cold horizontal surfaces $(\mathrm{e}=3 \mathrm{~cm})$. Since $\mathrm{W} / \mathrm{e}=1.33$, this distance is smaller than the natural wavelength. If the two large circulation flows located on both sides of the solid body are suppressed, for example by changing the adiabatic boundary conditions into hot wall temperature boundary conditions for $\mathrm{Ra}_{\mathrm{L}}=7.510^{4}$ $(\Delta \mathrm{T} \approx 0.75 \mathrm{~K})$ the two upper cells become unstable $\left(\mathrm{Ra}_{\mathrm{t}}=2025\right)$, and a new steady flow configuration takes place which is characterized by an overall circulation around the inner body. The two large lateral circulation cells have thus a stabilizing effect on the Rayleigh-Bénard convection above the heated inner body.

When the temperature difference is increased up to $\Delta \mathrm{T} \approx 2 \mathrm{~K}$, the Rayleigh number is beyond the critical value deduced from the linear stability theory. For larger $\Delta \mathrm{T}$, the steady flow displayed in Fig. 2a becomes unstable through a growing oscillatory disturbance and, finally, reaches a mono-periodic regime. Before describing the behavior of the flow as a function of time, let us first notice that the Rayleigh number based on the height between the hot and cold horizontal surfaces is equal to about $\mathrm{Ra}_{\mathrm{t}}=5400$ for $\Delta \mathrm{T}=2 \mathrm{~K}$, a value much smaller than $\mathrm{Ra}_{\mathrm{c}} \approx 3$ $10^{4}$, which is the critical value for the onset of oscillations for 2D Rayleigh-Bénard flows between infinite horizontal plates (Shan [19]). Thus, the transition in the present problem is probably not explained through classical Rayleigh-Bénard instability theories. When the Ra- 
number is increased, the intensities of the cells are strengthened, but proportionally more for the Rayleigh-Bénard cells than those for the lateral circulations. As a result, the lateral cells cannot restrain the size of the cells below the top cold wall.

Let us assume that a small perturbation amplifies the horizontal stretching of the left Rayleigh-Bénard cell with respect to the right one. This left cell (LHS) tends to recover its natural extension just above the heated body at the expense of the right cell (RHS). Because the right circulation flow is not strong enough to prevent displacement of the RHS Rayleigh-Bénard cell, this cell is shifted above the inner body toward the right upper corner of the cavity (Fig. 6a). Consequently, the size and intensity of the side circulation are considerably reduced. On the other hand, the circulation cell along the left wall being not blocked by the top Rayleigh-Bénard cell, it grows until the occurrence of an overall circulation around the heated body (Fig. 6b). Finally, the top RHS cell comes back above the inner body and ejects the left cell in the LHS upper corner (Fig. 6c).

While the oscillatory flow breaks the natural symmetry of the problem, this property may be recovered by averaging the flow field over an oscillation period. It should be noticed that this average solution is nevertheless different from the unstable steady flow (i.e. before the growth of the disturbances). The temporal variations of the vertical velocity component $v_{1}(t)$ and $v_{2}(t)$ at locations $\mathrm{P}_{1}(-0.22,0.35)$ and $\mathrm{P}_{2}(0.22,0.35)$, shown in Fig. 1 , were recorded and then used to compute the difference $\mathrm{v}_{1}(\mathrm{t})-\mathrm{v}_{2}(\mathrm{t})$. This signal centered upon zero can be viewed as a local symmetry indicator. Figure 7 shows its time variation for $\mathrm{Ra}_{\mathrm{L}}=2.1510^{5}$ : the amplitude of the oscillation growths exponentially at first, and becomes constant for $t>8.5$, showing an unsteady, asymptotic mono-periodic flow. It should be noted that the dimensionless frequency of this solution is equal to $15.9(0.0342 \mathrm{~Hz})$, about half of the values measured during the exponential growth, i.e. $32.1(0.0690 \mathrm{~Hz})$. The amplitudes of the oscillations are then extracted and drawn for unsteady flows at various Rayleigh numbers $\left(\mathrm{Ra}_{\mathrm{L}}=2.1510^{5}\right.$ in Fig. 8). The exponential development of a perturbation is clearly highlighted with a linear growth rate, obtained by a least mean square fit of the logarithm of the amplitudes, equal to 1.68. At dimensionless times $t>8.5$, the amplitudes of the oscillations become constant $\left(a(t)=a_{\infty}\right)$.

Similar amplitude analyses performed for various Rayleigh numbers allow the time variation of the growth rates in the exponential regime to be plotted (Fig 9, left axis) and the amplitudes of the oscillations for the asymptotic flows (Fig 9, right axis) as a function of $\mathrm{Ra}_{\mathrm{L}}$. The positive growth rates were obtained by starting the computations for a fluid initially at rest and at the 
uniform temperature $\mathrm{T}_{0}$, whereas oscillatory solutions were used to initialize the computations and calculate the negative values. From the growth rate analysis, the linear stability threshold $\mathrm{Ra}_{\mathrm{cl}}$ for the steady symmetric flow is found to be slightly greater than $\mathrm{Ra}_{\mathrm{L}}=210^{5}$. On the other hand, numerical simulations indicate that oscillatory solutions are also predicted for $\mathrm{Ra}_{\mathrm{L}}<\mathrm{Ra}_{\mathrm{cl}}$, until $\mathrm{Ra}_{\mathrm{L}}=1,7510^{5}$. For $\mathrm{Ra}_{\mathrm{L}} \leq 1.710^{5}$, the flow always converges toward a symmetrical, steady solution. From this study, it can be concluded that the steady solution is stable for finite amplitude perturbations if $\mathrm{Ra}_{\mathrm{L}} \leq \mathrm{Ra}_{\mathrm{c} 2}$, a critical Rayleigh number value located within the range $\left[\begin{array}{lll}1.7 & 10^{5}-1.7510^{5}\end{array}\right]$. For $\mathrm{Ra}_{\mathrm{c} 2}<\mathrm{Ra}_{\mathrm{L}}<\mathrm{Ra}_{\mathrm{c} 1}$, two established flows (periodic or steady) are thus possible according to the choice of the initial conditions. A hysteretic behavior for the fluid flow is therefore expected. It should be noted that the asymptotic mono-periodic regime is characterized by a dimensionless frequency which decreases linearly from $15.7(0.0338 \mathrm{~Hz})$ at $\mathrm{Ra}_{\mathrm{L}}=2.510^{5}$ to $14.4(0.0310 \mathrm{~Hz})$ at $\mathrm{Ra}_{\mathrm{L}}=3.510^{5}$.

\subsubsection{Effects of radiation}

As depicted previously for stable steady flows, increases in the effect of surface radiation lead to strengthen the intensity of the circulation cells along the vertical walls owing to the decrease in wall temperatures. Therefore, the circulation cells along the vertical walls increase with the wall emissivity and prevent the top cells from periodically moving from one side of the cavity to the other side. It can be concluded that surface radiation leads to larger critical Rayleigh numbers for the onset of the first bifurcation, as shown in Fig. 10 for emissivites of the cavity walls set to $\varepsilon_{\mathrm{c}}=$ $\varepsilon_{\mathrm{s}}=0.1$. The transitions between steady and oscillatory flows are shifted from $\mathrm{Ra}_{\mathrm{cl}}=210^{5}$ and $1.710^{5}<\mathrm{Ra}_{\mathrm{c} 2}<1.7510^{5}$ for pure natural convection (Fig. 9) to $\mathrm{Ra}_{\mathrm{c} 1}=3.1510^{5}$ and to $2.8510^{5}<$ $\operatorname{Ra}_{\mathrm{c} 2}<2.910^{5}$ for $\varepsilon_{\mathrm{c}}=\varepsilon_{\mathrm{s}}=0.1$ (Fig. 10), namely an increase of $50 \%$ in the stability threshold values.

\subsection{Effects of the inner body size}

Changes in the size of the inner body lead to large modifications in the flow structure. For a small body size, say $\mathrm{A} \leq 0.2$, Rayleigh-Bénard cells cannot develop above the top side and the flow turns into buoyant plume convection with interaction with the boundaries: for small enough Rayleigh numbers, the flow pattern is characterized by two counter-rotating, recirculating flows spreading over most of the flow domain, and separated by an ascending thermal plume which raises above the top wall. The results are thus similar to those discussed in Desrayaud and Lauriat [25] and Bouafia and Daube [7], with transition to unsteady flows beyond a critical value of the Rayleigh number. On account of the value of the Rayleigh number considered here $\left(\mathrm{Ra}_{\mathrm{L}}=\right.$ 
2. $10^{5}$ ), the flow is unsteady for $\mathrm{A}=0.2$ because $\mathrm{Ra}_{\mathrm{t}}=12,800$. The breaking of the reflection symmetry induces a swaying motion of the thermal plume which oscillates horizontally. Increases in the inner body size lead to smaller effective top and side Rayleigh numbers $\left(\mathrm{Ra}_{\mathrm{t}}\right.$ and $\mathrm{Ra}_{\mathrm{s}}$ ). Therefore, the fluid motions decrease along the side walls as well as in the top part of the cavity. The computations carried out for $0.3 \leq \mathrm{A} \leq 0.8$ confirmed these predictions. For $\mathrm{A}=0.3$, the flow exhibits a periodic behaviour. On the other hand, an almost pure conductive régime is obtained for $\mathrm{A}=0.8$ since $\mathrm{Ra}_{\mathrm{t}}=200$. In that case, Figure 11a shows that the fluid is fully thermally stratified below and above the inner body, and it is almost uniformly hot along the side walls.

When the effects of surface radiation are taken into account (in the case of a cavity with four black walls as in the experimental set-up used by Ménard [16] and Leplat [17]), the view factors between the horizontal and vertical black walls are reduced by increasing $\mathrm{A}$, and the effect of radiation exchanges amongst these surfaces decreases. On the other hand, the view factors between the hot vertical surfaces of the inner body and the cavity walls increases. However, the inner body emissivity being $\varepsilon_{\mathrm{h}}=0.05$, the radiation exchanges between the adiabatic walls and the hot vertical surfaces have a rather weak influence on the flow field. The overall result is that the side recirculation cells are strengthened whatever the aspect ratio provided that $A \geq 0.3$. For $\mathrm{A}=0.3$, a complex unsteady flow was predicted without radiation: the Rayleigh-Bénard cells oscillate and then merge into one or the other of the two side cells to produce a periodic fluid circulation around the inner body. A Fourier analysis of the signals at point $\mathrm{P}_{1}(-0.22,0.35)$ yields a fundamental frequency of this periodic flow equal to $\mathrm{f}=5.11(0.011 \mathrm{~Hz})$ with numerous harmonics. When surface radiation is taken into account, the flow is steady and exhibits then a symmetric motion about the vertical centerline of the cavity with two stable Rayleigh-Bénard cells below the top wall. Figure $11 \mathrm{~b}$ shows the effect of surface radiation on the conductive regime predicted for the largest aspect ratio considered $(\mathrm{A}=0.8)$ : the small temperature differences between the vertical walls produce weak recirculation cells. The largest effects of radiation occur at the four corner regions where the decreases in the adiabatic wall temperatures are the origin of the vertical fluid motion.

The averaged heat flux density at the inner body surfaces is reported in Table 3 for $0.3 \leq \mathrm{A} \leq 0.8$, with and without radiation taken into account. For $\mathrm{A}=0.3$ without radiation, the value reported in Table 3 is a time averaged heat flux obtained by integrating instantaneous data over one period. The increase in heat flux due to radiation is about $50 \%$ for $\mathrm{A}=0.3$ and $30 \%$ for $\mathrm{A}=0.8$. That is due in part to the radiation exchanges between the surfaces of the inner body and the 
cavity walls. However, the most significant result to be considered is the increase in the convective heat flux induced by the decrease in the temperatures of the adiabatic walls. The third line of Table 3 shows that effects of radiation on the increase in the convective part of the Nusselt number are reduced as the size of the inner body is increased, because the view factors between the cold horizontal walls and the vertical walls become smaller. However, it is clear that there is a critical aspect ratio above which the conductive heat transfer becomes dominant, as it is for $\mathrm{A}=0.8$.

The above results show that surface radiation exchanges strengthen the recirculation cells along the vertical side walls which, in turn, stabilize the flow fields. However, it should be underlined that these results are valid for the specific configuration studied here. By just changing the thermal boundary conditions, radiation exchanges could produce opposite effects (Mezrhab et al. [12]).

\section{Conclusion}

A numerical study of combined natural convection and surface radiation has been carried out with the aim at demonstrating the influence of radiation on the first transition to periodic flows which occurs in air-filled cavities when the Rayleigh number is increased. To this end, we have modeled an experimental set-up recently used to study the flow and heat transfer characteristics in a square cavity with an inner heated body. For this particular case, the stabilizing effect of radiation has been clearly demonstrated.

This work underlines that discrepancies between experimental and numerical results for gasfilled cavities may be explained just by having neglected the influence of surface radiation. We can conclude that it is highly difficult to properly interpret experimental results for gas-filled cavities with non isothermal boundary conditions. We believe that the present results can be extended for $3 \mathrm{D}$ flows as well as for turbulent natural convection flows (Ampofo and Karayiannis [26]).

\section{References}

[1] M. Rabhi, H. Bouali, A. Mezrhab, Radiation-natural convection heat transfer in inclined rectangular enclosures with multiple partitions. Energy Conversion and Management 49 (2008) 1228-1236.

[2] J.M. House, C. Beckerman, T.F. Smith, Effect of a centered conducting body on natural convection heat transfer in an enclosure. Numerical Heat Transfer Part A 18 (1990) 213-225. 
[3] Q.H. Deng, G.F. Tang, Numerical visualization of mass and heat transport for conjugate natural convection/heat conduction by streamline and heatline. International Journal of Heat and Mass Transfer 45 (2002) 2373-2385.

[4] M.Y. Ha, H.S. Yoon, K.S. Yoon, S. Balachandar, I. Kim, J.R. Lee, H.H. Chun, Twodimensional and unsteady natural convection in a horizontal enclosure with a square body. Numerical Heat Transfer Part A 41 (2002) 183-210.

[5] J.R. Lee, M.Y. Ha, A numerical study of natural convection in horizontal enclosure with a conducting body. International Journal of Heat and Mass Transfer 48 (2005) 3308-3318.

[6] J.R. Lee, M.Y. Ha, Numerical simulation of natural convection in a horizontal enclosure with a heat-generating conducting body. International Journal of Heat and Mass Transfer 49 (2006) 2684-2702.

[7] M. Bouafia, O. Daube, Natural convection for large temperature gradient around a square solid body within a rectangular cavity. International Journal of Heat and Mass Transfer 50 (2007) 3359-3615.

[8] H. Bouali, A. Mezrhab, H. Amaoui, M. Bouzidi, Radiation-natural convection heat transfer in an inclined rectangular enclosure. International Journal of Thermal Sciences 45 (2006) 553-566

[9] D.R. Chenoweth, S. Paolucci, Natural convection in an enclosed vertical air layer with large horizontal temperature differences, Journal of Fluid Mechanics 169 (1986) 173-210.

[10] G. Lauriat, G. Desrayaud, Effect of surface radiation on conjugate natural convection in parially open enclosures. International Journal of Thermal Sciences 45 (2006) 335-346.

[11] A. Mezrhab, S. Amraqui, C. Abid, Modelling of surface radiation and natural convection in a vented « $T$ » form cavity. International Journal of Heat Fluid Flow 31 (2010) 83-92.

[12] A. Mezrhab, H. Bouali, H. Amoui, M. Bouzidi, Computation of combined naturalconvection and radiation heat-transfer in a cavity having a square body at its center. Applied Energy 83 (2006) 1004-1023.

[13] G. Colomer, M. Costa, R. Consul, A. Oliva, Three-dimensional numerical simulation of convection and radiation in a differentially heated cavity using the discrete ordinates method. International Journal of Heat and Mass Transfer 47 (2004) 257-269.

[14] G. Cesini, M. Paroncini, G. Cortelle, M. Manzan, Natural convection from a horizontal cylinder in a rectangular cavity. International Journal of Heat and Mass Transfer 42 (1999) 18011811.

[15] G. Leplat, Ph. Barricau, Ph. Reulet, P. Millan, Natural convection around a heated squaresection cylinder in an enclosure: visualization and dynamic characterization of instabilities by Particle Image Velocimetry. Proceedings of the ASME Summer Heat Transfer Conference, Jacksonville, USA (2008) Paper number 56219.

[16] V. Ménard, Convection naturelle dans une cavité contenant une source de chaleur. PhD thesis, Université de Toulouse (2005).

[17] G. Leplat, Stabilité d'un écoulement de convection naturelle en milieu confiné. $\mathrm{PhD}$ thesis, Université de Toulouse (2009).

[18] G. Leplat, E. Laroche, Ph. Reulet, P. Millan, Numerical simulation of an unsteady confined natural convection flow. Proceedings of the ASME Summer Heat Transfer Conference, San Francisco, USA (2009) Paper number 88001.

[19] R.B. Bird, W.E. Steward, E.N. Lightfoot, Transport Phenomena, $2^{\text {nd }}$ Ed.,Wiley \& Sons (2002) Chap. 16, 487-512

[20] M.F. Modest, Radiative Heat Transfer, $2^{\text {nd }}$ Ed., Academic Press (2003) Chap. 5, 162-197

[21] Ansys Fluent 12 User'Guide (n.d), www.fluentusers.com 
[22] B.P. Leonard, A stable and accurate convection modelling procedure based on quadratic upstream interpolation. Computer Methods in Applied Mechanics and Engineering, 19(1) (1979) 59-98

[23] R.I Issa, Solution of the implicitly discretized fluid-flow equations by operator-splitting. Journal of Computational Physics 62(1) (1986) 40-65.

[24] X. Shan, Simulation of Rayleigh-Bénard convection using a lattice Boltzmann method. Physical Review E 55(3) (1997) 2780-2788.

[25] G. Desrayaud, G. Lauriat, Unsteady confined buoyant plumes. Journal of Fluid Mechanics. 252 (1993) 617-646.

[26] F. Ampofo, T.G. Karayiannis, Experimental benchmark data for turbulent natural convection in an air filled square cavity, International Journal of Heat and Mass Transfer 46 (2003) 3551-3572. 


\section{Table captions}

Table 1 Effect of the grid resolution on the average Nusselt numbers at the isothermal surfaces (see Fig. 1) in the case $\mathrm{A}=0.4, \mathrm{Ra}=2.10^{5}$ for pure natural convection.

Table 2 Average convective Nusselt numbers at the various surfaces (see Fig. 1) in the case A = $0.4, \mathrm{Ra}=2.10^{5}$ for pure natural convection and for combined natural convection and radiation. The last column is for cold isothermal side walls.

Table 3 Effect of the body size on the average Nusselt number at the inner body surface in the case $\mathrm{Ra}=2 \cdot 10^{5}\left(\Delta \mathrm{Nu}_{\mathrm{cv}}\right.$ is the increase in the convective Nusselt number due to surface radiation). 


\section{Figure captions}

Figure 1 Schematic of the system of interest: a square, heated inner-body centred within a square cavity.

Figure 2 Comparisons between streamlines and isothermal patterns for pure natural convection at $\mathrm{Ra}_{\mathrm{L}}=2.10^{5}$ (a), combined convection and surface radiation $\left[(\mathrm{b}) \varepsilon_{\mathrm{c}}=0.05, \varepsilon_{\mathrm{s}}=1\right.$ and (c) $\left.\varepsilon_{\mathrm{c}}=\varepsilon_{\mathrm{s}}=1\right]$ and for cold vertical side walls (d). Isotherms and streamlines equally spaced $\left(\Psi_{\mathrm{n}}=0.3856 \pm \mathrm{n} \times 0.7713\right.$ for the streamline contours, the dashed lines indicate clockwise circulations).

Figure 3 Effect of surface radiation on the dimensionless temperature distributions along the vertical, adiabatic side-walls at $\mathrm{Ra}_{\mathrm{L}}=2.10^{5}$.

Figure 4 Variation of the maximum streamfunction for the side wall circulations as a function of emissivity of the cavity walls $\left(\varepsilon_{\mathrm{c}}=\varepsilon_{\mathrm{s}}=\varepsilon\right)$ at $\mathrm{Ra}_{\mathrm{L}}=3.10^{5}$. The continuous line is for steady, symmetric flow structures.

Figure 5 3D-isothermal patterns $\left(T_{h}=299.15 \mathrm{~K}\right.$ in red, $T_{c}=297.15 \mathrm{~K}$ in dark blue $)$ for three cross sections $\left(\mathrm{z}^{*}=-4.50 \mathrm{~cm}, \mathrm{z}^{*}=0, \mathrm{z}^{*}=4.5 \mathrm{~cm}\right)$ of the parallelepipedic cavity $(10 \mathrm{~cm} \times 10 \mathrm{~cm}$ $\times 18 \mathrm{~cm})$ at $\mathrm{Ra}_{\mathrm{L}}=2.10^{5}(\mathrm{a})$ : pure natural convection, $(\mathrm{b})$ : combined convection and surface radiation $\left(\varepsilon_{\mathrm{c}}=\varepsilon_{\mathrm{s}}=1\right)$.

Figure 6 Characteristic flows and temperature patterns over a period for supercritical pure natural convection $\left(\mathrm{A}=0.4, \mathrm{Ra}_{\mathrm{L}}=2.1510^{5}\right)$ Isotherms and streamlines equally spaced $\left(\Psi_{\mathrm{n}}=0.3856 \pm \mathrm{n} \times 0.7713\right.$ for the streamline contours, the dashed lines indicate clockwise circulations).

Figure 7 Time variation of the difference between the vertical velocity components at point $\mathrm{P}_{1}$ and $\mathrm{P}_{2}$ shown in Fig. $1\left(\mathrm{Ra}=2.1510^{5}, \mathrm{~A}=0.4\right.$, pure natural convection).

Figure 8 Variation of the logarithm of the amplitude disturbance, a(t), versus dimensionless time for $\mathrm{Ra}_{\mathrm{L}}=2.1510^{5}$ and $\mathrm{A}=0.4$ (pure natural convection). $\tau_{\mathrm{g}}$ is the linear growth rate and $\mathrm{a}_{\infty}$ the amplitude of the asymptotic periodic flow. Open circles denotes numerical results, the full line is the least mean square fit.

Figure 9 Linear growth rate of the disturbances (left axis, filled square) and amplitude of the disturbance for the asymptotic flow (right axis, cross-symbols) versus the Rayleigh number for pure natural convection.

Figure 10 Linear growth rate of the disturbances (left axis, filled square) and amplitude of the disturbance for the asymptotic flow (right axis, cross-symbols) versus the Rayleigh number for combined surface radiation and natural convection $\left(\varepsilon_{\mathrm{c}}=\varepsilon_{\mathrm{s}}=0.1\right)$.

Figure 11 Comparisons between streamlines and isothermal patterns for pure natural convection in the case $\mathrm{A}=0.8$ and $\mathrm{Ra}_{\mathrm{L}}=2.10^{5}$ (a), combined convection and surface radiation for $\varepsilon_{\mathrm{c}}=\varepsilon_{\mathrm{s}}=1$ (b) $\left(\Psi_{1}= \pm 0.07713\right.$ for the streamline contours, the dashed lines indicate clockwise circulations). 


\section{TABLES}

\begin{tabular}{|l|c|c|c|c|}
\hline Mesh & $100 \times 100$ & $150 \times 150$ & $200 \times 200$ & $250 \times 250$ \\
\hline Side A'B'or C'D' & 3.7044 & 3.7107 & 3.7143 & 3.7165 \\
\hline Side A'D' (bottom) & 5.6550 & 5.6456 & 5.6405 & 5.6374 \\
\hline Side B'C' (top) & 9.5066 & 9.4764 & 9.4657 & 9.4608 \\
\hline Bottom wall (AD) & 2.5334 & 2.5345 & 2.5349 & 2.5352 \\
\hline Top wall (BC) & 6.4948 & 6.4829 & 6.4790 & 6.4773 \\
\hline
\end{tabular}

Table 1 Effect of the grid resolution on the average Nusselt numbesr at the isothermal surfaces (see Fig. 1) in the case $\mathrm{A}=0.4, \mathrm{Ra}=2.10^{5}$ for pure natural convection.

\begin{tabular}{|l|c|c|c|c|c|c|}
\hline Emissivity & $\varepsilon_{\mathrm{c}}=\varepsilon_{\mathrm{s}}=0$ & $\varepsilon_{\mathrm{c}}=\varepsilon_{\mathrm{s}}=0.05$ & $\varepsilon_{\mathrm{c}}=\varepsilon_{\mathrm{s}}=0.1$ & $\varepsilon_{\mathrm{c}}=0.05, \varepsilon_{\mathrm{s}}=1$ & $\varepsilon_{\mathrm{c}}=\varepsilon_{\mathrm{s}}=1$ & $\mathrm{~T}_{\mathrm{s}}=\mathrm{T}_{\mathrm{c}}$ \\
\hline Side A'B' or C'D' & 3.7174 & 3.7601 & 3.9955 & 4.1719 & 6.2773 & 8.2144 \\
\hline Side A'D' (bottom) & 5.6347 & 5.6876 & 5.9172 & 6.0218 & 8.0667 & 11.0136 \\
\hline Side B'C' (top) & 9.4614 & 9.4726 & 9.4807 & 9.5454 & 9.4448 & 9.3594 \\
\hline Bottom wall (AD) & 2.5346 & 2.5738 & 2.4910 & 2.9873 & 1.4540 & 0.6020 \\
\hline Top wall (BC) & 6.4778 & 6.4875 & 6.4770 & 6.6339 & 6.3673 & 6.1314 \\
\hline Side Wall & 0 & $-5.410^{-3}$ & -0.1937 & +0.0288 & -2.1026 & 3.7373 \\
\hline
\end{tabular}

Table 2 Average convective Nusselt numbers at the various surfaces (see Fig. 1) in the case $\mathrm{A}=$ $0.4, \mathrm{Ra}=2.10^{5}$ for pure natural convection and for combined natural convection and radiation. The last column is for cold isothermal side walls. 


\begin{tabular}{|l|c|c|c|c|}
\hline \multicolumn{1}{|c|}{$\mathrm{A}$} & 0.3 & 0.4 & 0.6 & 0.8 \\
\hline $\mathrm{Nu}(\varepsilon=0)$ & $6.4169 *$ & 5.6303 & 4.2322 & 5.8985 \\
\hline $\mathrm{Nu}\left(\varepsilon_{\mathrm{c}}=\varepsilon_{\mathrm{S}}=1\right)$ & 9.6709 & 8.5481 & 6.4180 & 7.8931 \\
\hline$\Delta \mathrm{Nu}_{\mathrm{cv}}$ & 2.2030 & 1.8835 & 1.1988 & 1.2199 \\
\hline $\mathrm{Nu}_{\mathrm{r}}\left(\varepsilon_{\mathrm{c}}=\varepsilon_{\mathrm{s}}=1\right)$ & 1.0510 & 1.0343 & 0.9870 & 0.7747 \\
\hline
\end{tabular}

* mean value for an oscillatory flow

Table 3 Effect of the body size on the average Nusselt number at the inner body surface in the case $\mathrm{Ra}=2 \cdot 10^{5}\left(\Delta \mathrm{Nu}_{\mathrm{cv}}\right.$ is the increase in the convective Nusselt number due to surface radiation). 


\section{FIGURES}

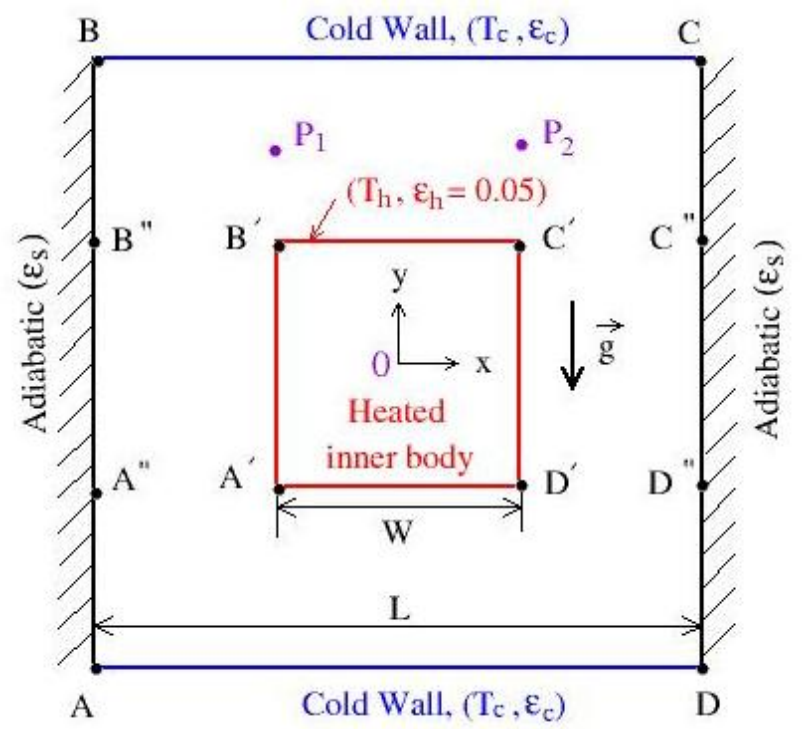

Figure 1 Schematic of the system of interest: a square, heated inner-body centred within a square cavity. 

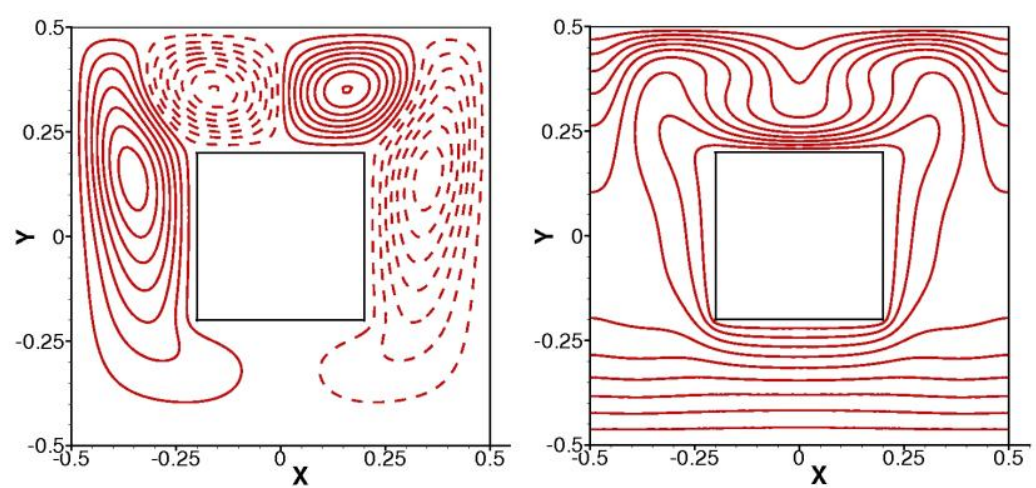

(a)
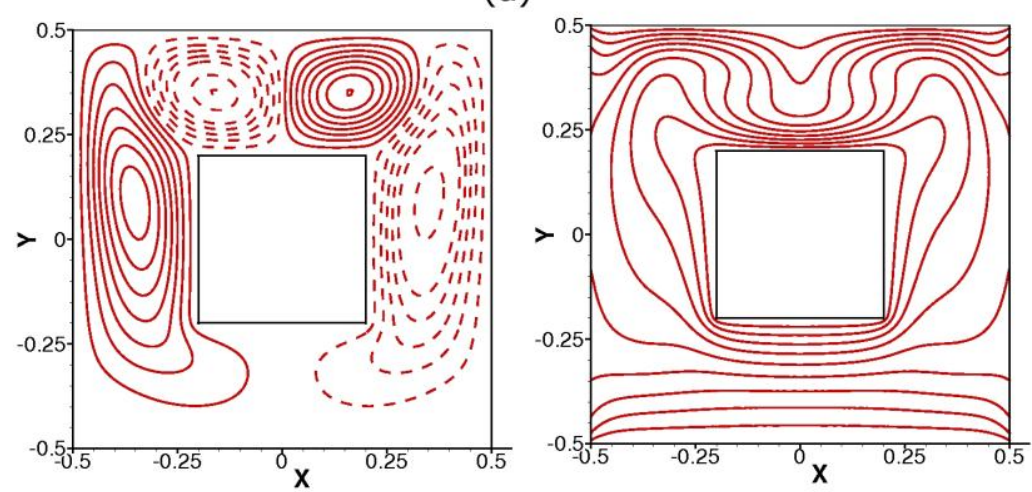

(b)
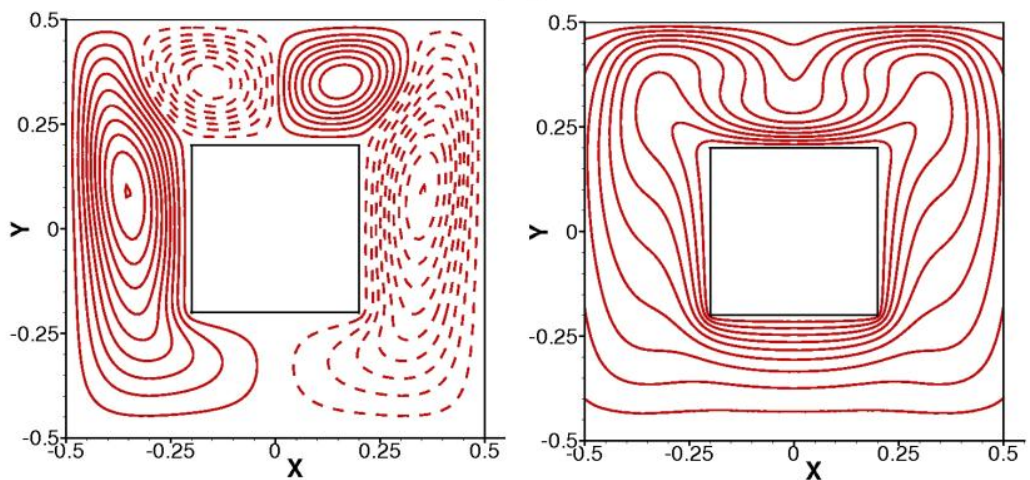

(c)
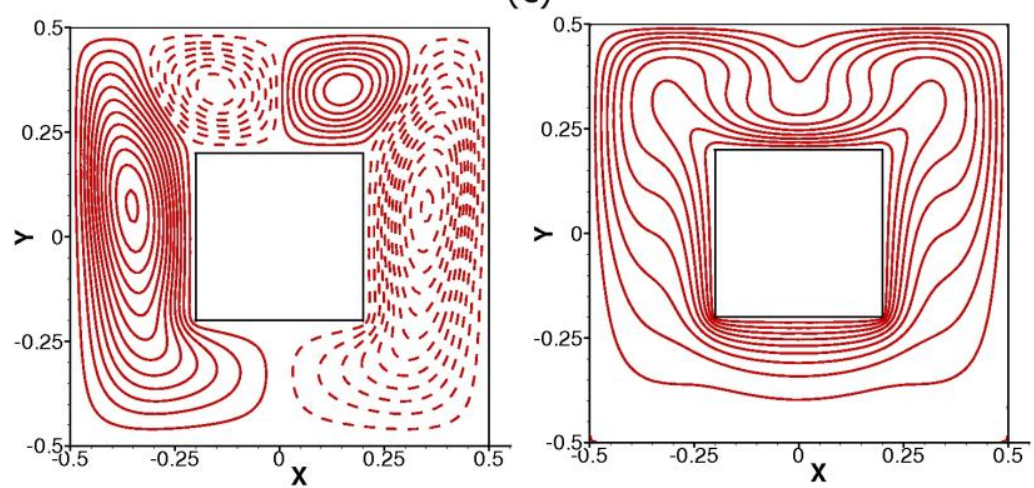

(d)

Figure 2 Comparisons between streamlines and isothermal patterns for pure natural convection at $\mathrm{Ra}_{\mathrm{L}}=2.10^{5}$ (a), combined convection and surface radiation $\left[(\mathrm{b}) \varepsilon_{\mathrm{c}}=0.05, \varepsilon_{\mathrm{s}}=1\right.$ and (c) $\left.\varepsilon_{\mathrm{c}}=\varepsilon_{\mathrm{s}}=1\right]$ and for cold vertical side walls (d). Isotherms and streamlines equally spaced $\left(\Psi_{\mathrm{n}}=0.3856 \pm \mathrm{n} \times 0.7713\right.$ for the streamline contours, the dashed lines indicate clockwise circulations). 


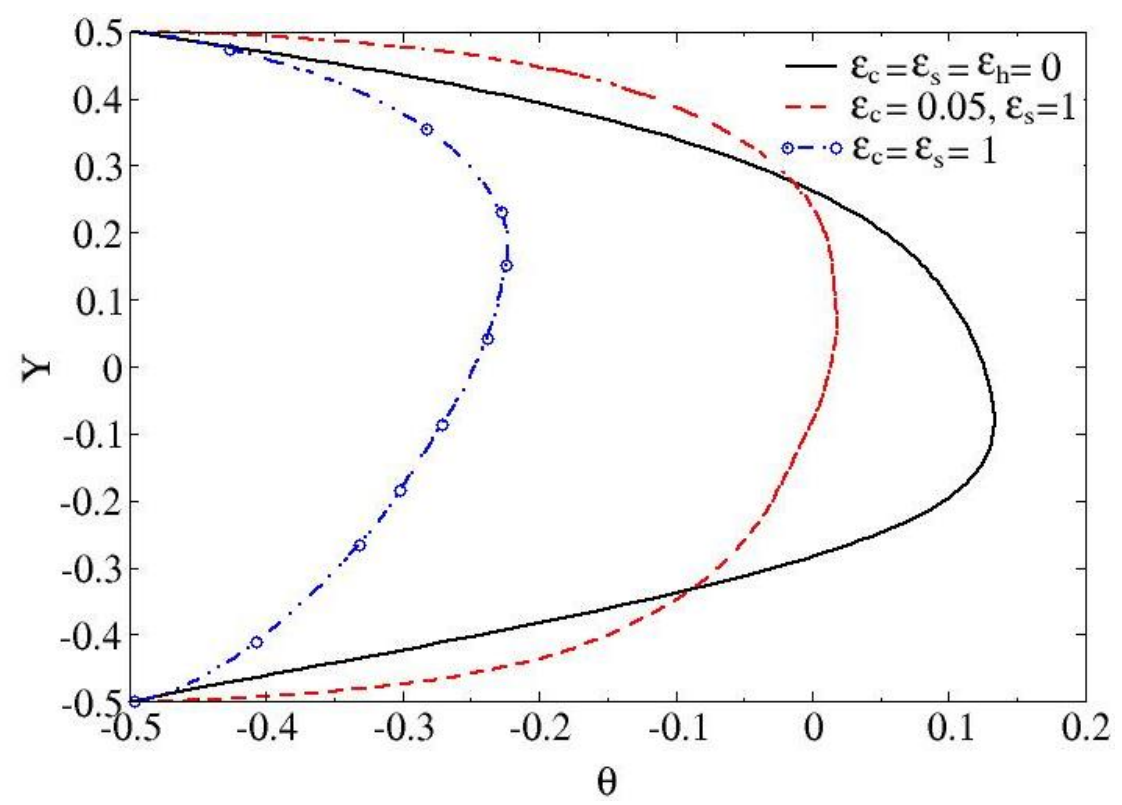

Figure 3 Effect of surface radiation on the dimensionless temperature distributions along the vertical, adiabatic side-walls at $\mathrm{Ra}_{\mathrm{L}}=2 \cdot 10^{5}$.

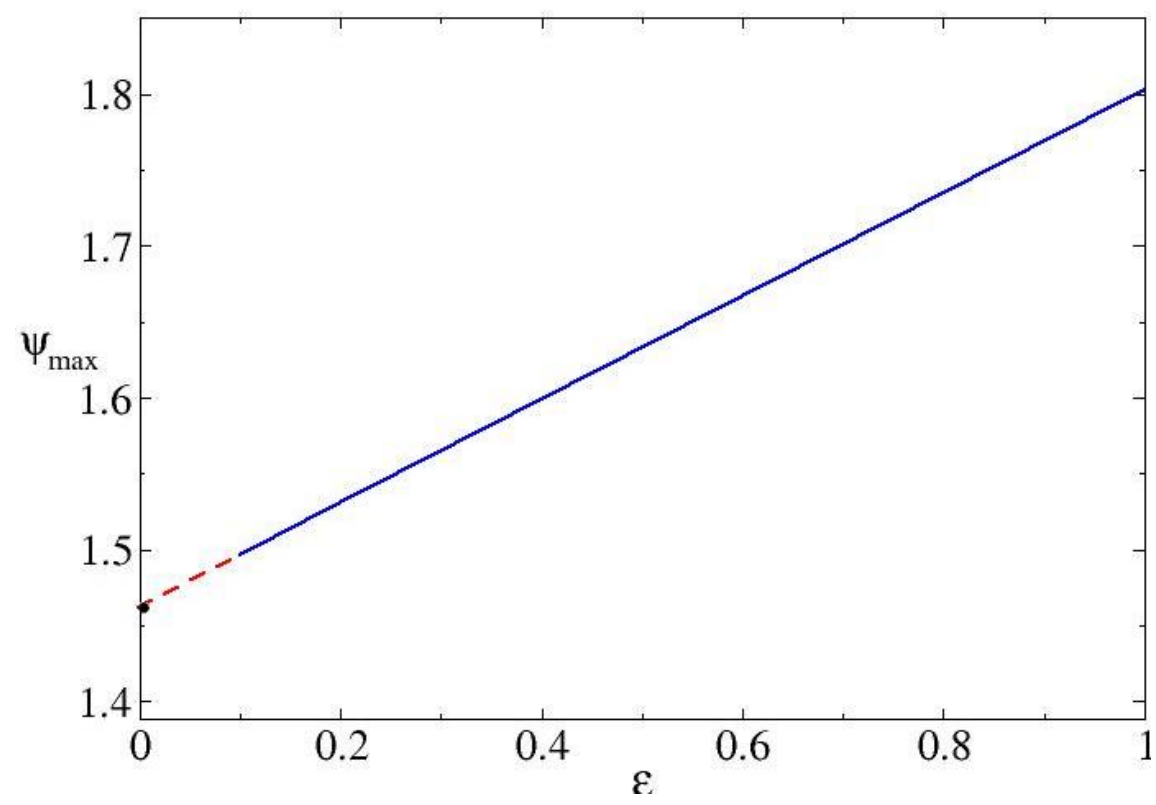

Figure 4 Variation of the maximum streamfunction for the side wall circulations as a function of emissivity of the cavity walls $\left(\varepsilon_{\mathrm{c}}=\varepsilon_{\mathrm{s}}=\varepsilon\right)$ at $\mathrm{Ra}_{\mathrm{L}}=3.10^{5}$. The continuous line is for steady, symmetric flow structures. 


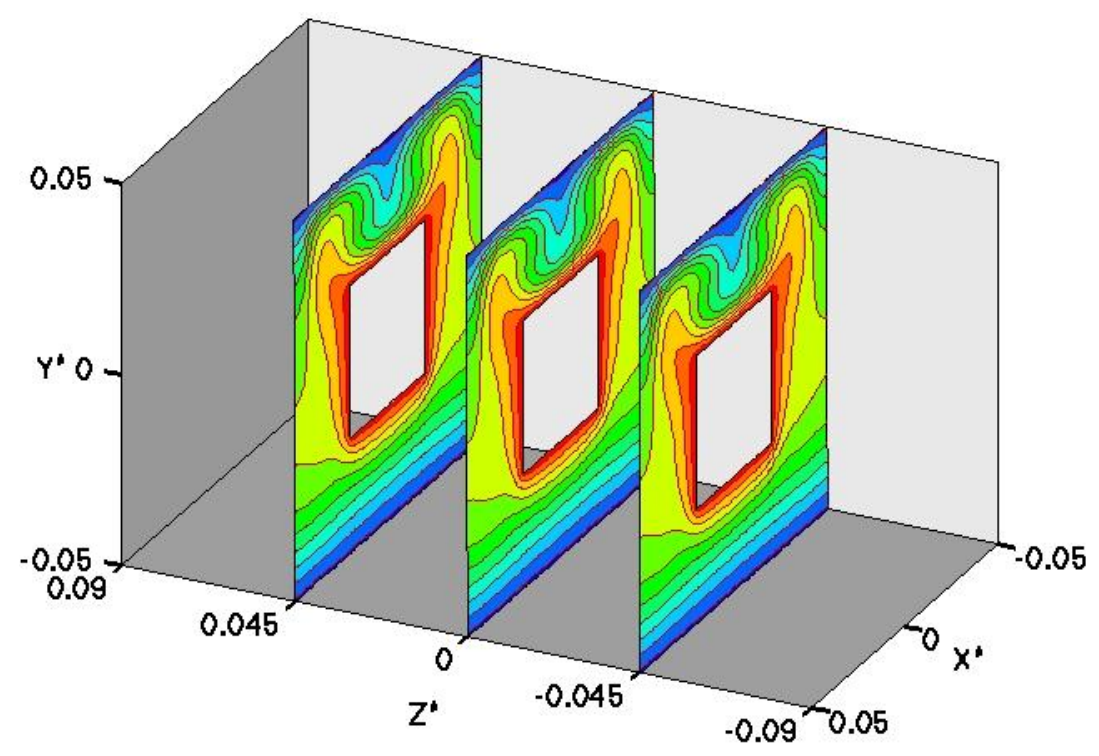

(a)

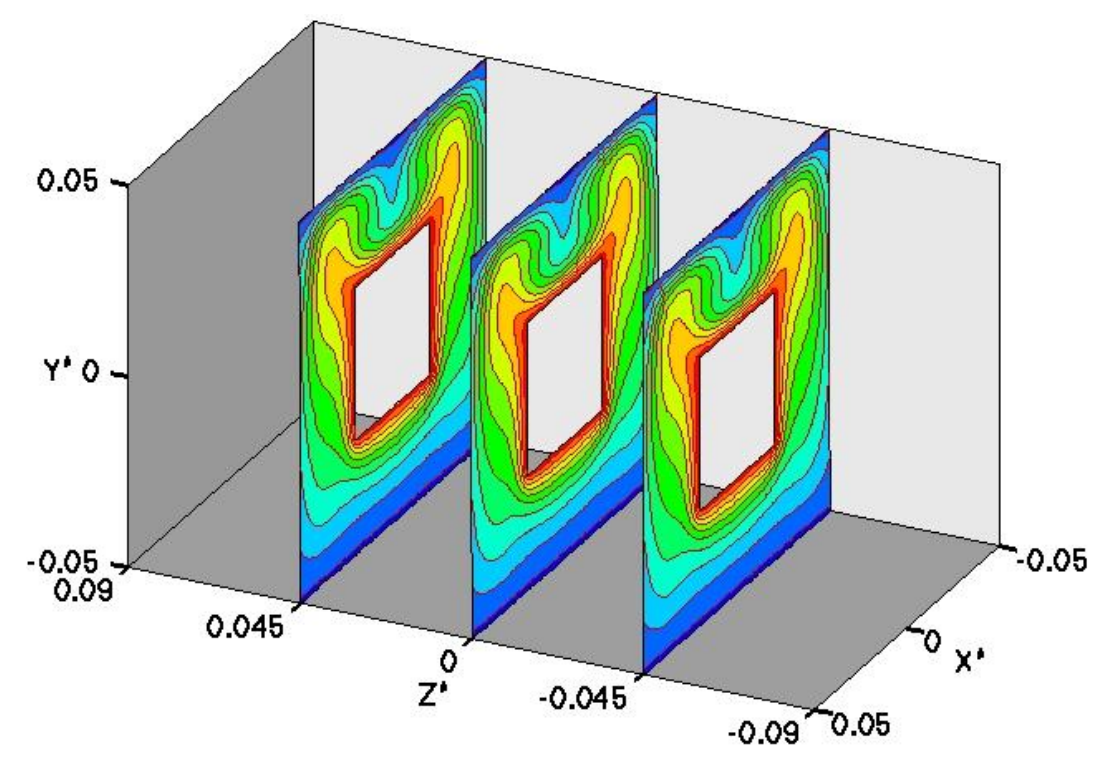

(b)

Figure 5 3D-isothermal patterns $\left(T_{h}=299.15 \mathrm{~K}\right.$-red, $T_{c}=297.15 \mathrm{~K}$-dark blue $)$ for three cross sections $\left(\mathrm{z}^{*}=-4.50 \mathrm{~cm}, \mathrm{z}^{*}=0, \mathrm{z}^{*}=4.5 \mathrm{~cm}\right)$ of the parallelepipedic cavity $(10 \mathrm{~cm} \times 10 \mathrm{~cm} \times 18$ $\mathrm{cm})$ at $\mathrm{Ra}_{\mathrm{L}}=2 \cdot 10^{5}(\mathrm{a})$ : pure natural convection, $(\mathrm{b})$ : combined convection and surface radiation $\left(\varepsilon_{\mathrm{c}}=\varepsilon_{\mathrm{s}}=1\right)$. 

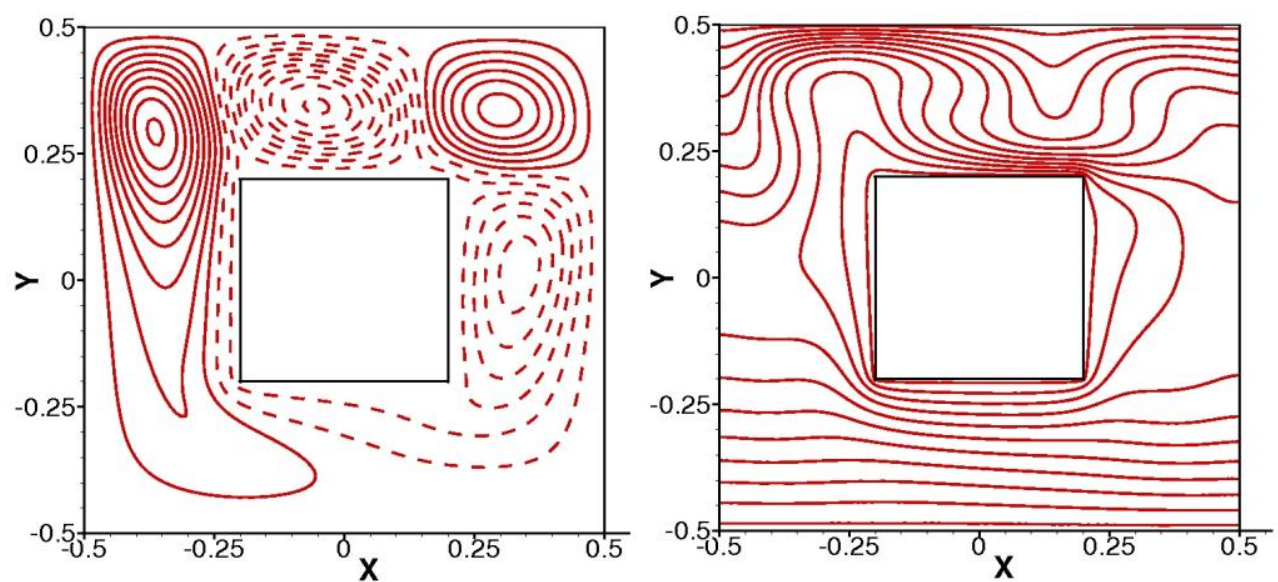

(a)
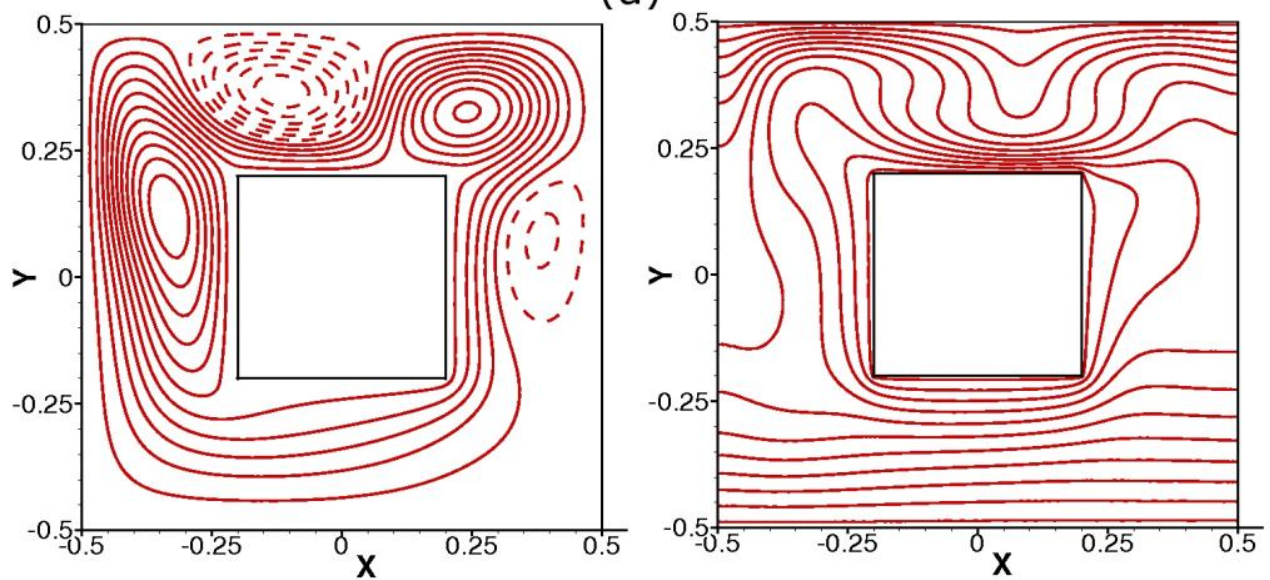

(b)
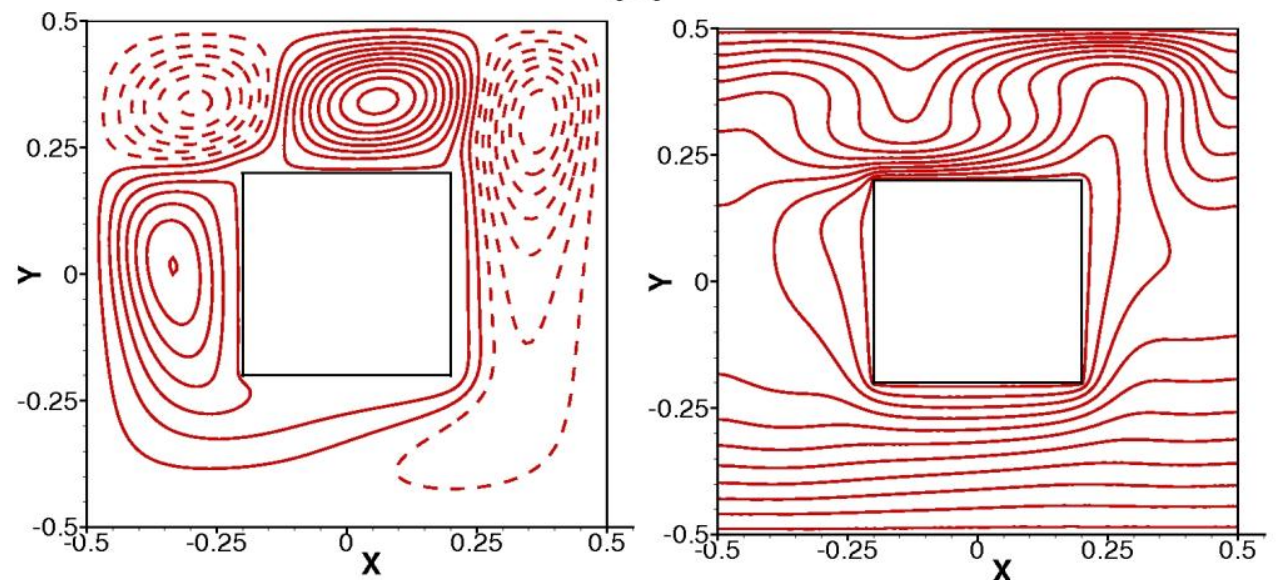

(c)

Figure 6 Characteristic flows and temperature patterns over a period for supercritical pure natural convection $\left(\mathrm{A}=0.4, \mathrm{Ra}_{\mathrm{L}}=2.1510^{5}\right)$ Isotherms and streamlines equally spaced $\left(\Psi_{\mathrm{n}}=0.3856 \pm \mathrm{n} \times 0.7713\right.$ for the streamline contours, the dashed lines indicate clockwise circulations). 


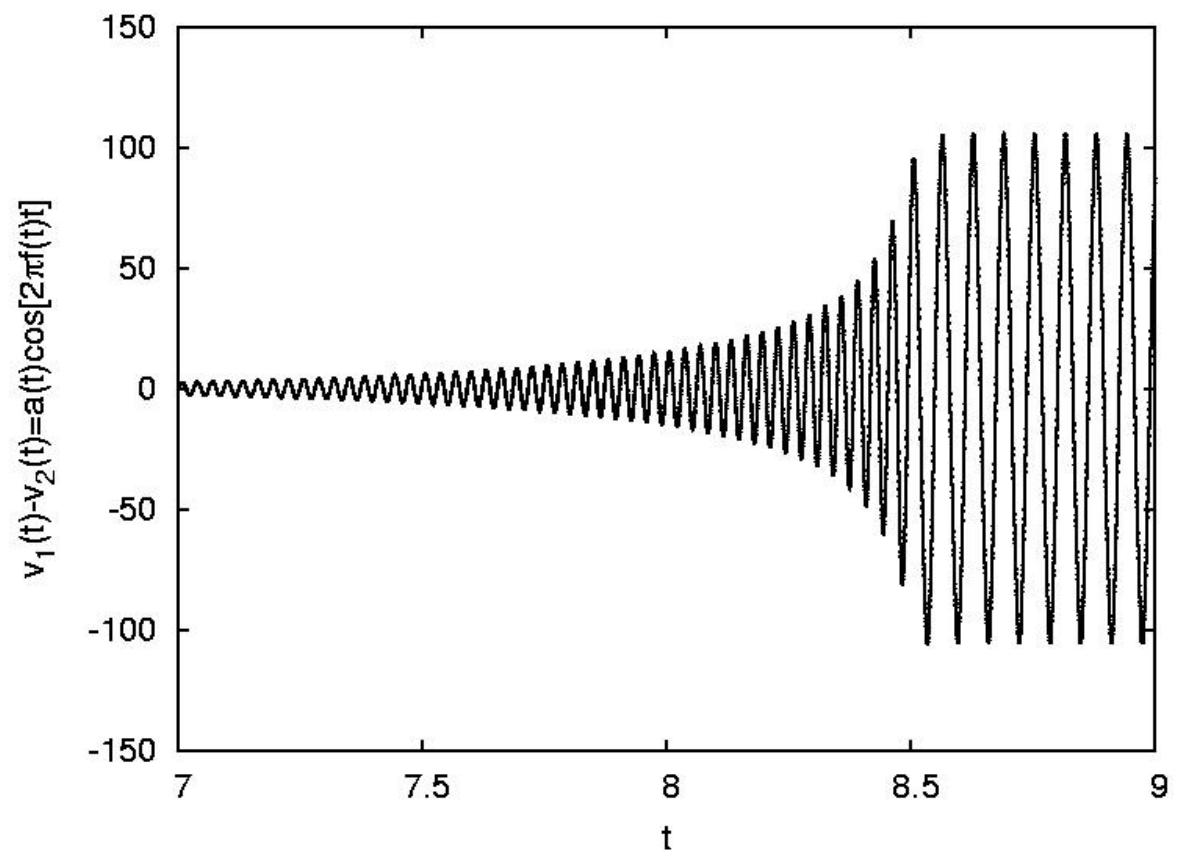

Figure 7 Time variation of the difference between the vertical velocity components at point $\mathrm{P}_{1}$ and $\mathrm{P}_{2}$ shown in Fig. $1\left(\mathrm{Ra}=2.1510^{5}, \mathrm{~A}=0.4\right.$, pure natural convection).

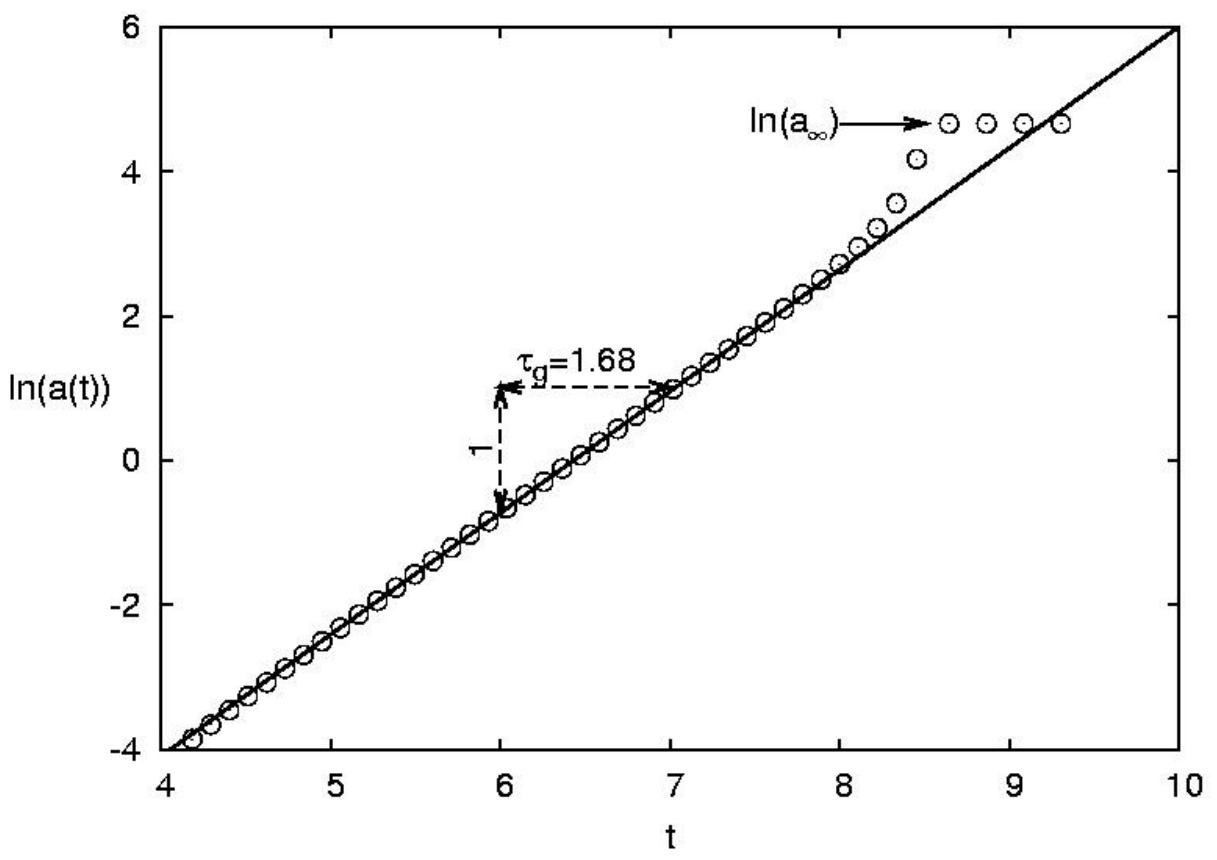

Figure 8 Variation of the logarithm of the amplitude disturbance, a(t), versus dimensionless time for $\mathrm{Ra}_{\mathrm{L}}=2.1510^{5}$ and $\mathrm{A}=0.4$ (pure natural convection). $\tau_{\mathrm{g}}$ is the linear growth rate and $\mathrm{a}_{\infty}$ the amplitude of the asymptotic periodic flow. Open circles denotes numerical results, the full line is the least mean square fit. 


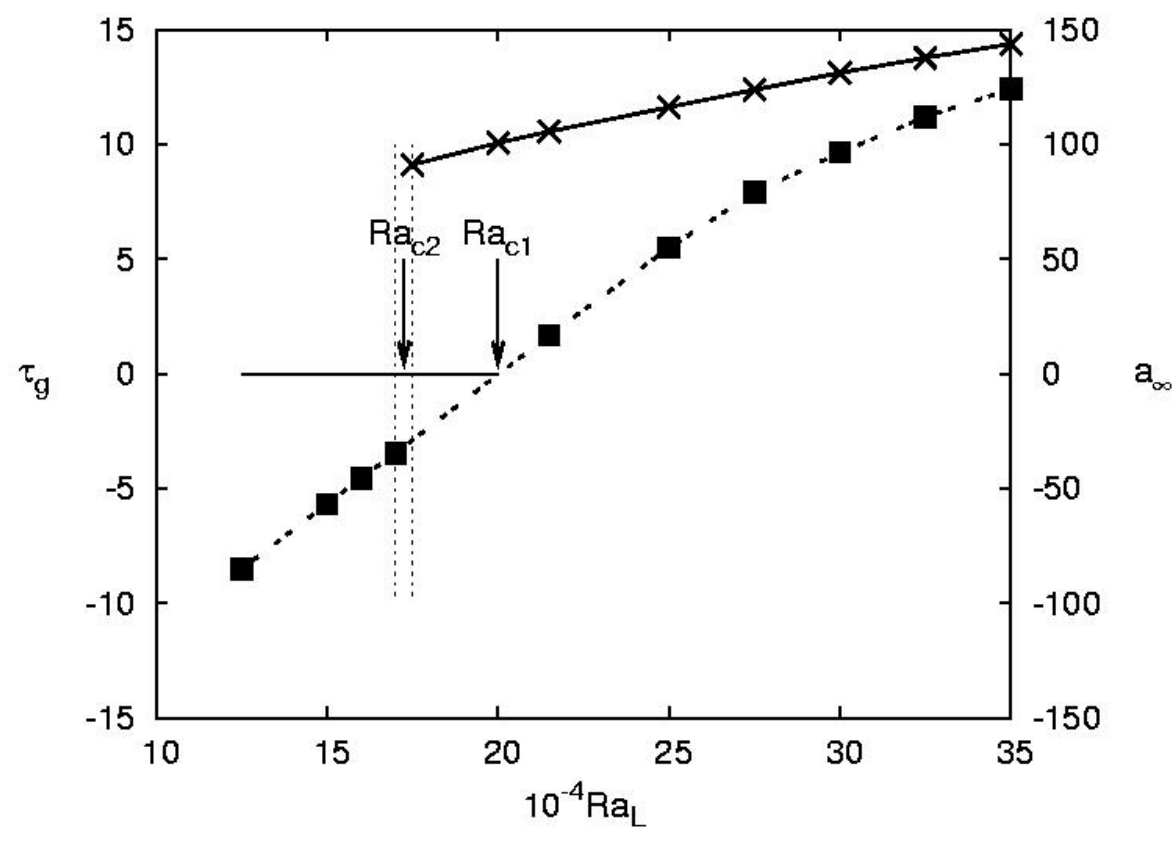

Figure 9 Linear growth rate of the disturbances (left axis, filled square) and amplitude of the disturbance for the asymptotic flow (right axis, cross-symbols) versus the Rayleigh number for pure natural convection.

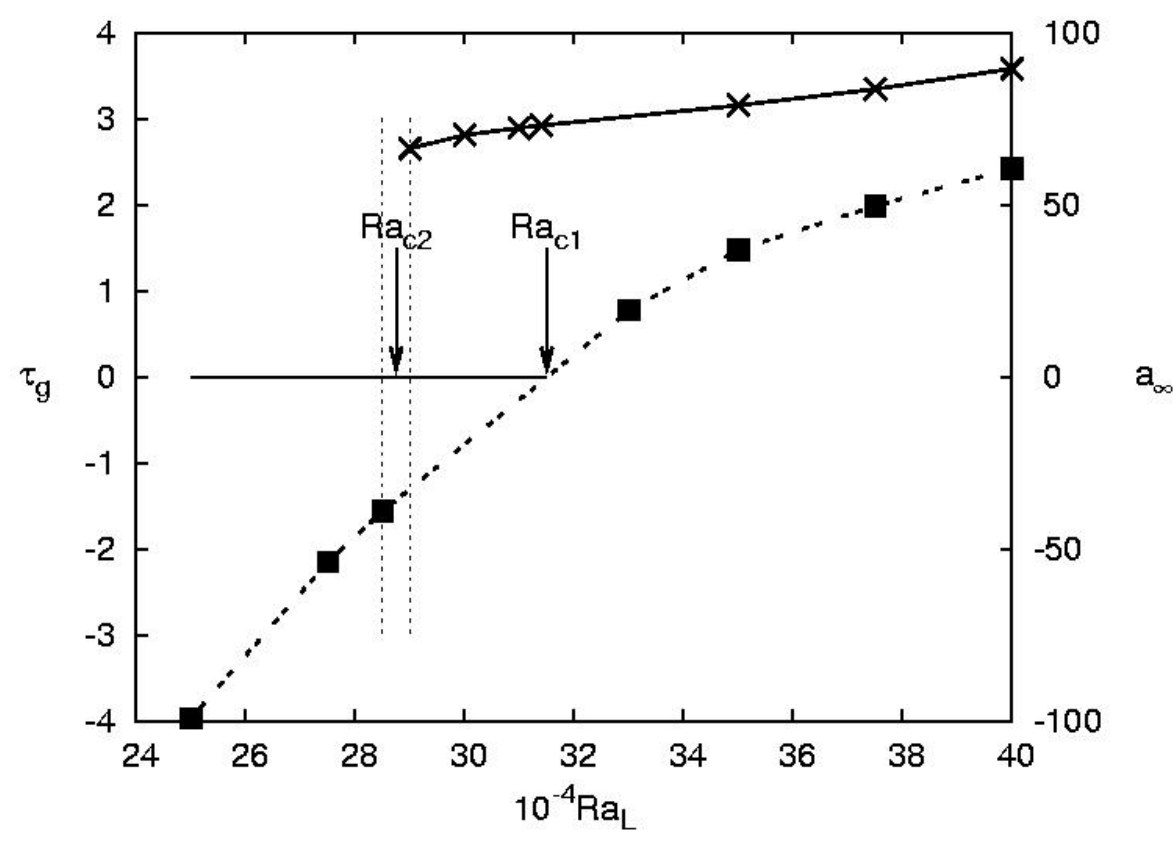

Figure 10 Linear growth rate of the disturbances (left axis, filled square) and amplitude of the disturbance for the asymptotic flow (right axis, cross-symbols) versus the Rayleigh number for combined surface radiation and natural convection $\left(\varepsilon_{\mathrm{c}}=\varepsilon_{\mathrm{s}}=0.1\right)$. 

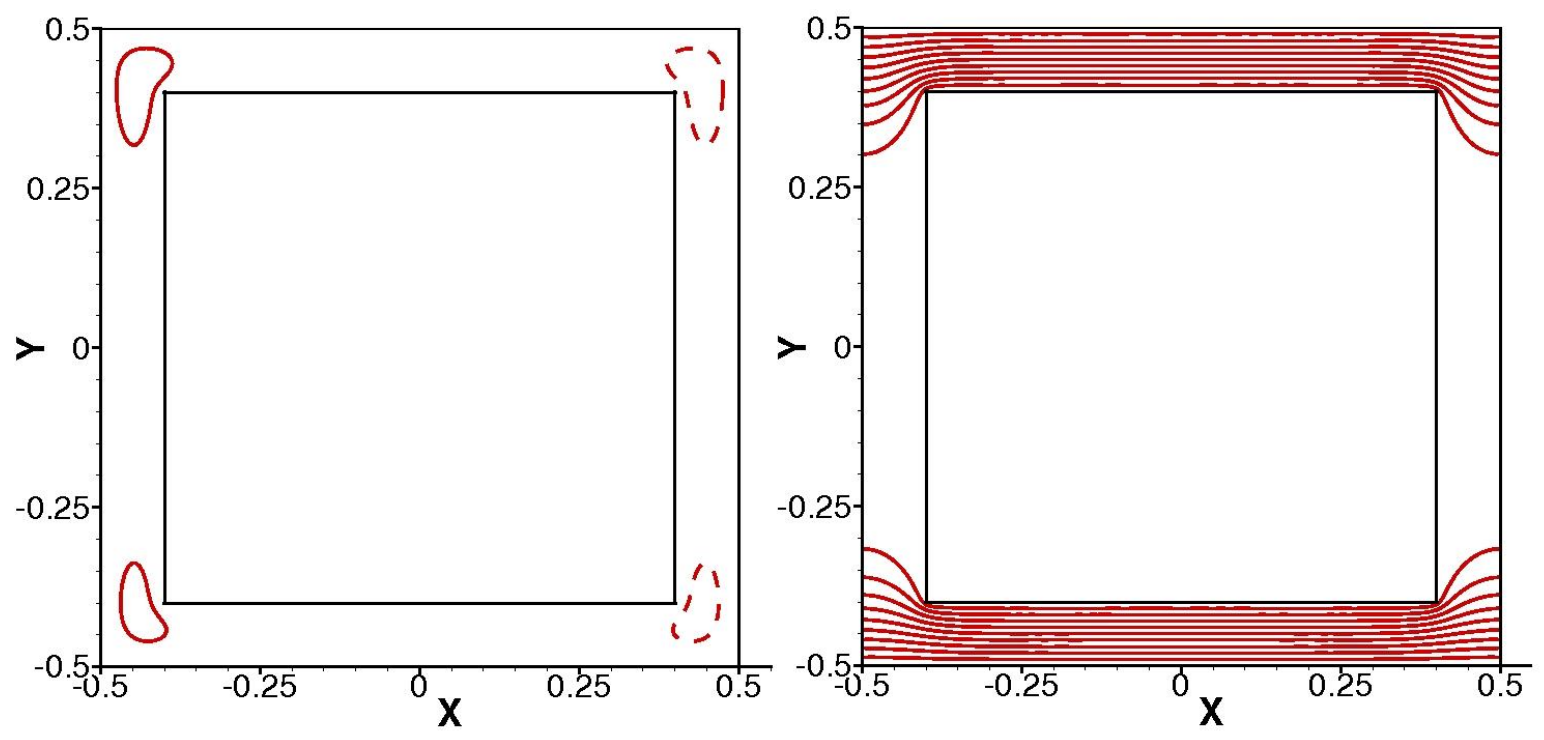

(a)
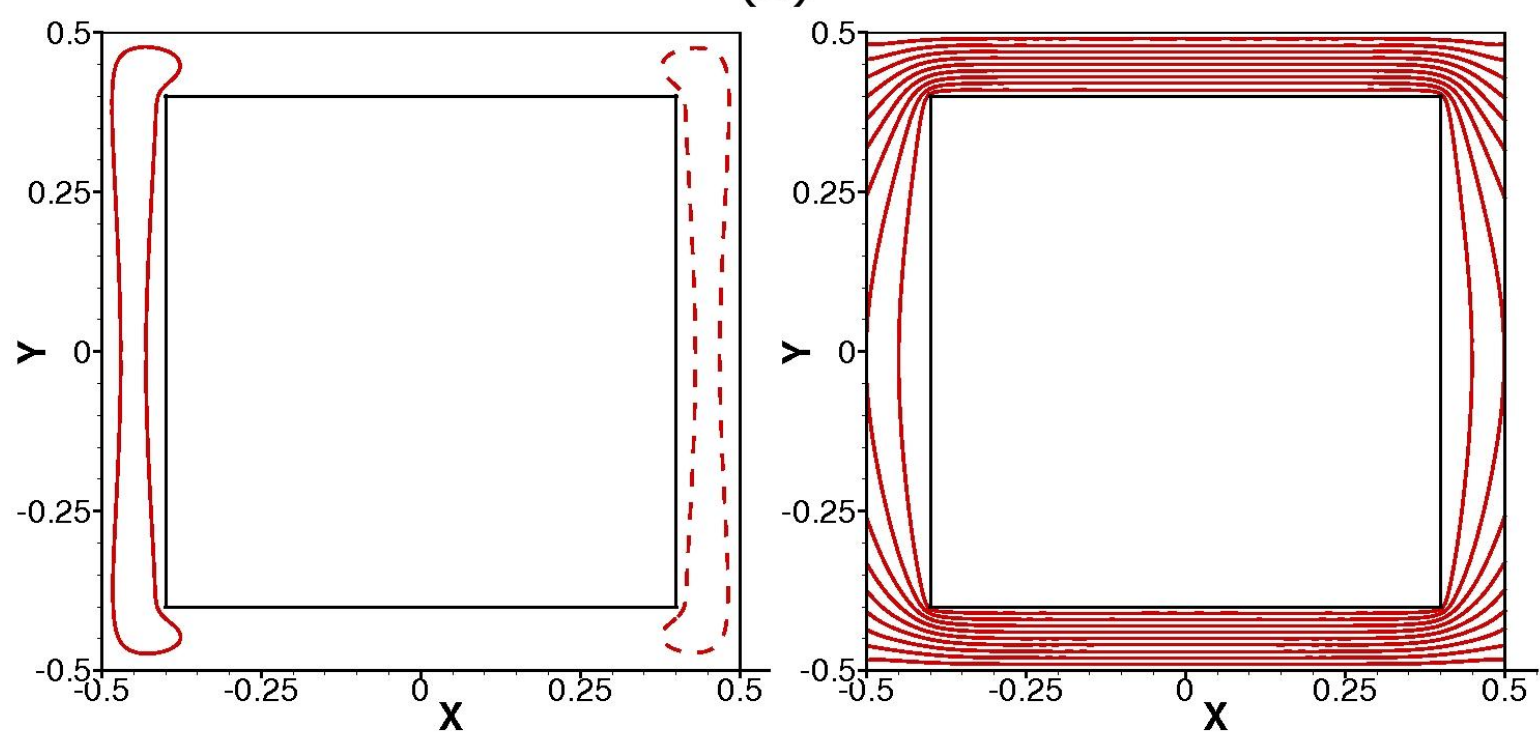

(b)

Figure 11 Comparisons between streamlines and isothermal patterns for pure natural convection in the case $\mathrm{A}=0.8$ and $\mathrm{Ra}_{\mathrm{L}}=2.10^{5}$ (a), combined convection and surface radiation for $\varepsilon_{\mathrm{c}}=\varepsilon_{\mathrm{s}}=1$ (b) $\left(\Psi_{1}= \pm 0.07713\right.$ for the streamline contours, the dashed lines indicate clockwise circulations). 